\title{
Recent Developments in the Reduction of Unsaturated Bonds by Magnesium Precursors
}

Indrani Banerjee ${ }^{\mathrm{a}}$ and Tarun K. Panda*a

a Department of Chemistry, Indian Institute of Technology Hyderabad, Kandi, Sangareddy 502285, Telangana, India.

\begin{abstract}
Scientists have witnessed significant breakthroughs in $s$-block metal chemistry. Over the past few years, several applications in catalysis associated with alkaline-earth metal catalysts have been established owing to their abundance and lower cost. These catalysts have proved to be essential alternatives to transition metal catalysts. Several research groups have recognized the importance of magnesium complexes as highly active metal catalysts in the reduction of a series of unsaturated substrates for the synthesis of ubiquitous compounds necessary for industrial purposes. This minireview presents, based on studies published in the past recent years, a detailed discussion of catalytic hydroelementation on $\mathrm{C}-\mathrm{X}(\mathrm{X}=\mathrm{C}, \mathrm{N}, \mathrm{O}, \mathrm{S})$ multiple bonds, promoted by novel magnesium metal catalysts.
\end{abstract}

\section{Introduction}

Broad area of research have been blooming in recent years in several fields of chemistry. Researchers have taken the challenge of developing smooth and facile methodologies, which can be readily utilized for the synthesis of new compounds. Compounds obtained from multistep reaction procedures do not lead to sustainable growth and thus the advancement of greener approaches is required. ${ }^{1}$ The alternative strategies that would uphold resource recovery and enhance efficiency are crucial for sustainable chemistry. ${ }^{2}$ The designing of eco-friendly and nontoxic metal catalysts that add up to higher efficiency in catalytic procedures are much desired and are gradually being recognized. ${ }^{3}$ These synthetic procedures are associated with minimized sideproducts and other stoichiometric wastes. ${ }^{4}$ The emergence of catalysis therefore became the predominant tool for the synthetic chemists around the globe beneficial for both science and daily lives.

The importance of catalysis have been acknowledged in chemical industries, medicinal chemistry, material sciences, and several areas of organic, inorganic, and organometallic chemistry is indisputable. ${ }^{5}$ Over the years, a library of homogeneous and heterogeneous catalysts gained from 
transition metals have been established, familiar in many significant catalytic reactions. ${ }^{6}$ However, the inadequacy, high price and toxic properties are related to these precious metal precursors. In addition, the deposition of heavy metals in the resulting products continue to be problematic in atom-economic methodologies. ${ }^{7}$ This motivated scientists to design appropriate earth-abundant metal catalyst systems that led to the growth of many novel chemical reactions. The catalysts are emphasized for the advancement in reaction strategies, such as the abundance of resources, enhancement of efficiency, simplicity of methods, and product selectivity. Thus, earth abundant metals mediated catalytic conversions of several small molecules into corresponding valuable products have paved for sustainable approach. ${ }^{8}$ Main group elements such as $s$-block elements and early transition metals present the most abundant elements in the earth's crust and possess diverse properties in the periodic table. It has been observed in numerous recent discoveries that the properties of main group metal complexes are analogous to that of transition metal complexes. ${ }^{9}$ As a result, considerable utilization of the said metal catalysts have been discovered progressively for various applications. ${ }^{10-14}$

\subsection{Growth of $s$-block metal catalysts.}

Although numerous $s$-block metal complexes have gained recognition from many scientists, progress in exploring their chemistry as organometallic compounds have been sluggish. ${ }^{15}$ An attractive aspect of the $s$-block elements are the low +1 and +2 oxidation states, which are advantageous in the catalytic cycles. Nonetheless, inadequate synthetic proficiency, high susceptibility toward air and moisture, and short-lived reactive species are some factors that limit their use in synthetic procedures in the laboratory and therefore, their utilization are underdeveloped. ${ }^{16}$ Over the years, lighter congeners of alkali and alkaline earth metals have seen substantial progress due to improved stability of complexes through proper molecular design. ${ }^{17}$ Metal hydrides as reactive intermediates were isolated, acting as crucial precursors and reducing agents in broad areas of organic and inorganic chemistry. A series of hydroelementation reactions on olefins, ${ }^{18}$ atom-economical cross-dehydrocoupling (CDC) reactions, ${ }^{19}$ polymerizations of styrenes and dienes,${ }^{20}$ ring-opening polymerizations (ROP) of various cyclic esters have been the beneficiaries. ${ }^{21}$ The current trend in synthetic chemistry shows the applicability of group 2 metals in catalysis, due to their abundance, low cost, and environmentally benign nature. ${ }^{22}$ However, despite factors giving them an advantage, alkaline-earth metals such as $\mathrm{Mg}(\mathrm{II})$ metal precursors have gained limited recognition in catalysis. ${ }^{23}$ The proper tuning and designing of ancillary ligands 
to magnesium metal precursors made them suitable for a variety of hydroelementation reactions on multiple bonds. ${ }^{24}$

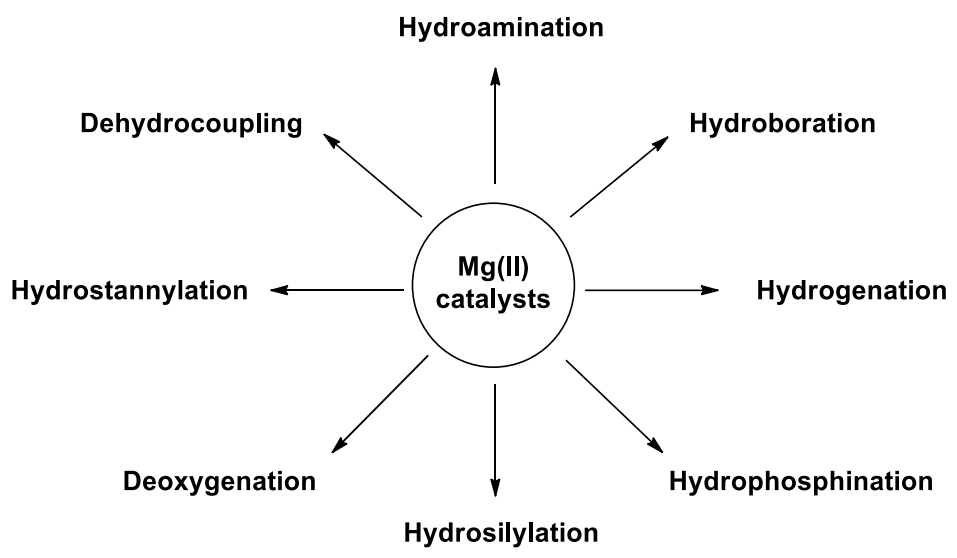

Figure 1. Various applications of $\mathrm{Mg}(\mathrm{II})$ metal catalysts.

\subsection{Development of hydroelementation reactions.}

In the organic synthetic methods being followed currently, scientists have been focusing intensely on catalytic carbon-heteroatom bond formation. ${ }^{25}$ In recent years, catalytic hydroelementation reactions resulting from the reduction of various unsaturated substrates have been noteworthy. The addition of $\mathrm{E}-\mathrm{H}$ substrates $(\mathrm{E}=\mathrm{N}, \mathrm{O}, \mathrm{S}, \mathrm{P}, \mathrm{C}, \mathrm{Si}, \mathrm{B})$ to multiple bonds afford many essential products that represent atom-economical approaches. Over the past two decades, substantial acceleration in hydrofunctionalization reactions have been discovered. ${ }^{26}$ The synthesis of the $\mathrm{C}$-heteroatom bond formation represents a variety of reactions such as hydroamination, ${ }^{27}$ hydroboration, ${ }^{28}$ hydrosilylation, ${ }^{29}$ hydrothiolation, ${ }^{30}$ alkyne oligomerizations, ${ }^{31}$ and many more. Many transition-metal, lanthanide, actinide catalysts have been well recognized for the hydroelementation reactions of alkenes and alkynes. ${ }^{32-40}$ Over the years, researchers around the globe have developed proficient alkali metal catalysts for hydrofunctionalization reactions of unsaturated substrates. ${ }^{41-45}$ Figure 2 displays the various alkali metal and alkaline-earth metal complexes that have been recognized as useful catalysts for numerous hydroelementation reactions. 


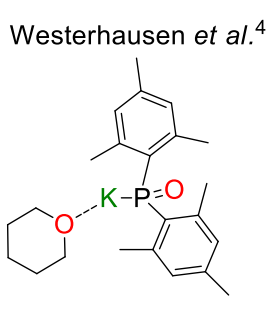

Carpentier et al. ${ }^{46}$

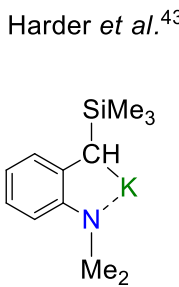

Hill et al. ${ }^{47}$

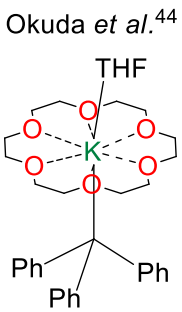

Hill et al. ${ }^{48}$
Panda et al. ${ }^{51 \mathrm{~b}, \mathrm{~g}}$

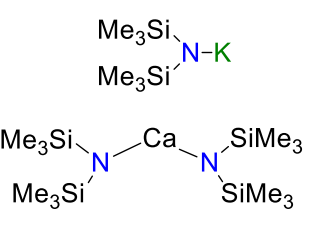

Cui et al. ${ }^{49}$

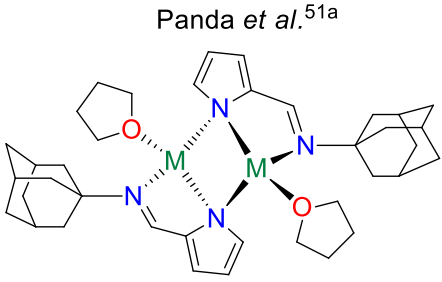

$\mathrm{M}=\mathrm{Li}, \mathrm{Na}$

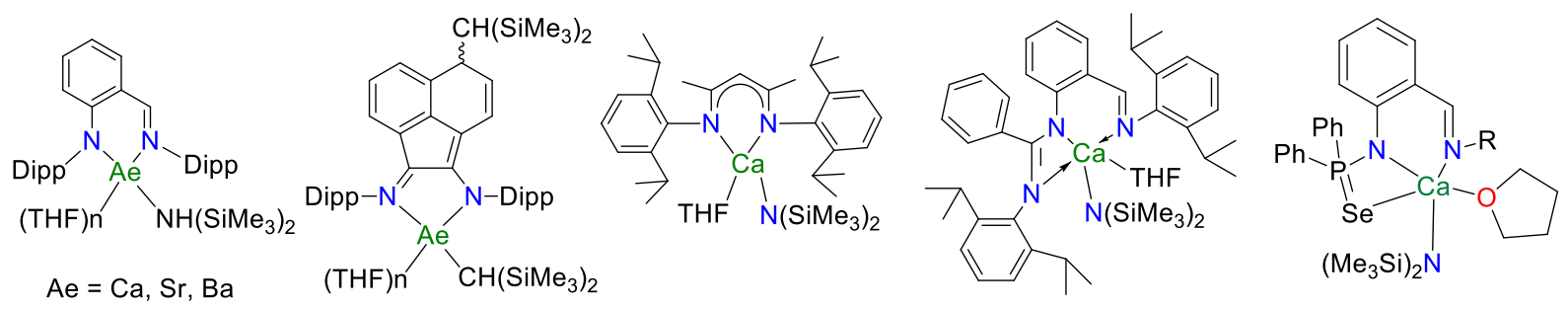

$$
\mathrm{Ae}=\mathrm{Mg}, \mathrm{Ca}, \mathrm{Sr}
$$
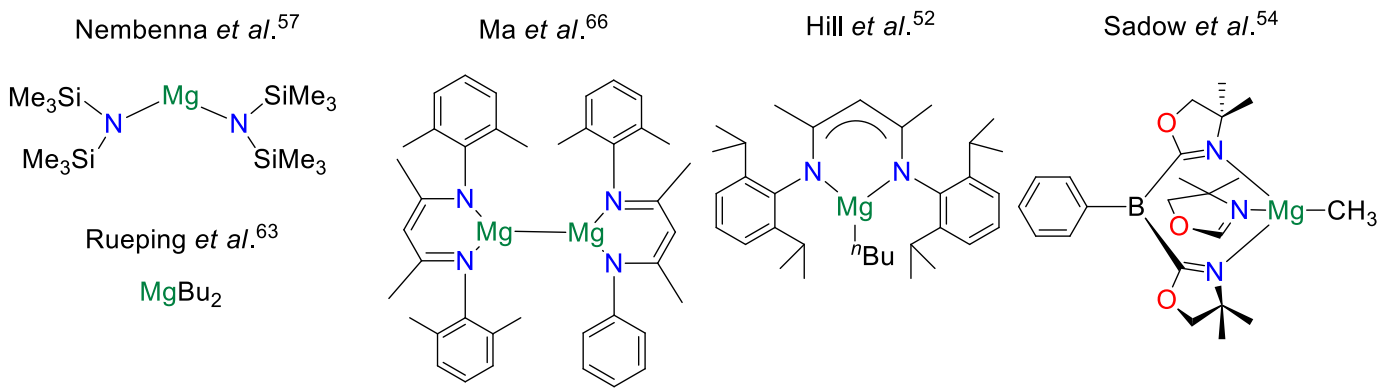

Figure 2. Various novel alkali and alkaline-earth metal catalysts for several hydroelementation reactions of unsaturated substrates.

Research involving the group 2 metals, especially $\mathrm{Ca}(\mathrm{II}), \mathrm{Sr}(\mathrm{II})$, and $\mathrm{Ba}(\mathrm{II})$ metal precursors have also flourished for several catalytic applications. ${ }^{46-49}$ Over the past years, our research group has been developing a series of efficient alkali and alkaline earth metal catalysts for the functionalization of unsaturated substrates. ${ }^{50-51}$ This paper will provide a recent accumulative report on various hydroelementation reaction strategies promoted by a variety of magnesium metal precursors over the last decade.

\section{Magnesium-catalyzed reduction of unsaturated substrates.}

The landmark contribution for the development of the hydrofunctionalization reactions by novel magnesium metal catalysts was catered by Hill, Harder, and Sadow research groups and this field of research is still emerging. 


\subsection{Hydroelementation reactions of compounds with $\mathrm{C}=\mathrm{O}$ and $\mathrm{C}=\mathrm{N}$ functional groups.}

A $\beta$-diketiminato-derived magnesium alkyl complex 1 was demonstrated by Hill and coworkers as the potent precatalyst for the reduction of aliphatic and aromatic aldehydes and ketones. Minimal catalyst loading under ambient reaction condition was subjected for the hydroboration reaction protocol (Scheme 1). ${ }^{52}$ The initial studies of the mechanism revealed the formation of a heteroleptic magnesium hydride complex 2, generated by B-H/C-Mg metathesis, as the active catalyst onto which the carbonyl group attaches. The hydridomagnesium species and a variable magnesium borohydride intermediate of the $\left[{ }^{n} \mathrm{BuHBpin}\right]^{-}$exist in equilibrium.
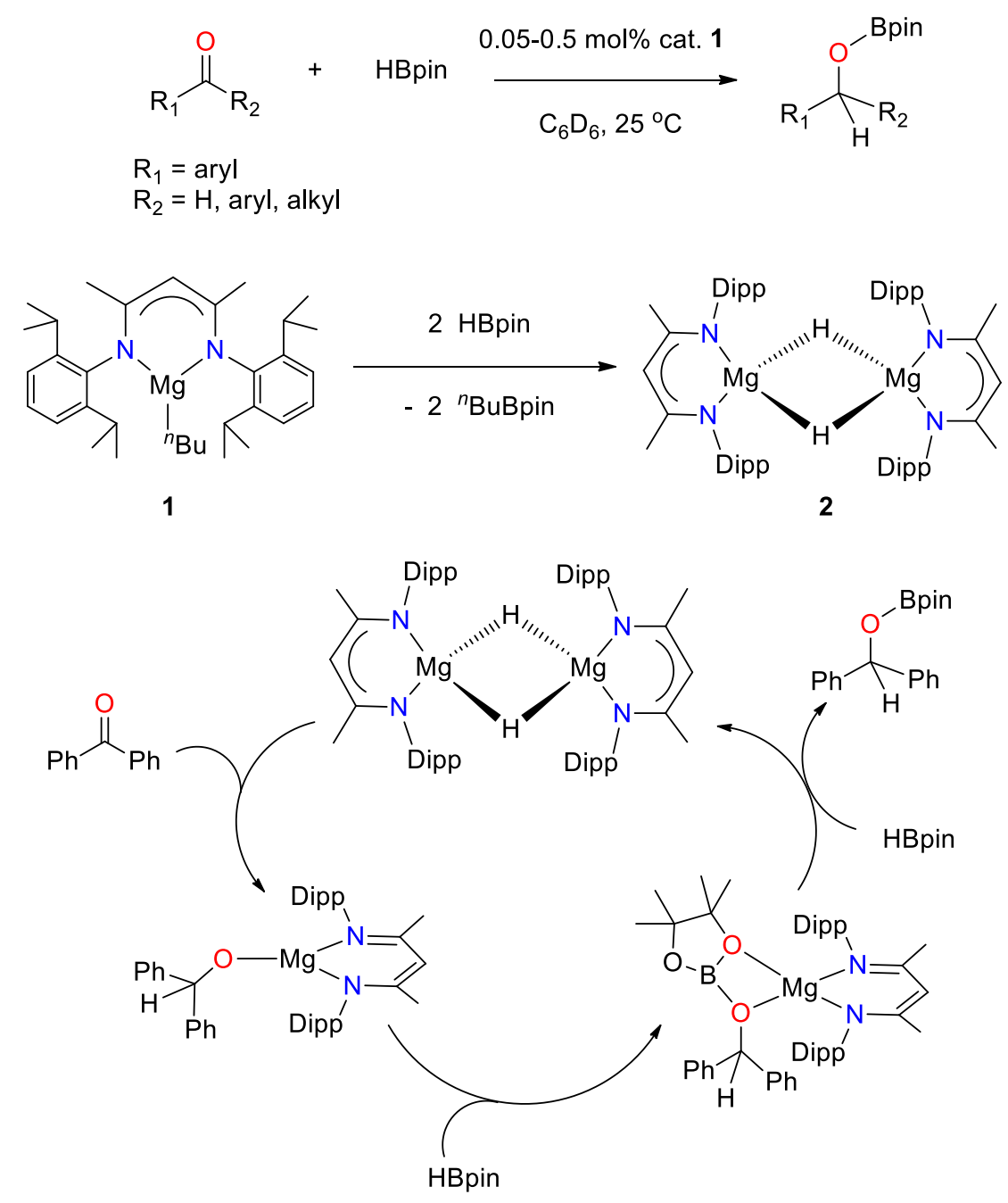

Scheme 1. $\mathrm{Mg}(\mathrm{II})$-catalyzed reduction of carbonyl compounds.

Harder et al. represented reduction of pyridine and its derivatives via hydroboration. The reactions were promoted by fascinating multinuclear $\beta$-diketiminate magnesium hydride 
complexes controlled by the nature of bridging ligand. ${ }^{53}$ Selective hydride transfer in 2-position of pyridine producing $\mathrm{NN}-[\mathrm{Mg}(1,2-\mathrm{DHP})]_{2}$. (pyridine) 2 (DHP = dihydridopyridide) caused from the dearomatization of stoichiometric amount of pyridine and tetranuclear magnesium cluster [NN$\left.(\mathrm{MgH})_{2}\right]_{2}\left[\mathrm{NN}=\left\{\left(2,6-{ }^{i} \mathrm{Pr}_{2} \mathrm{C}_{6} \mathrm{H}_{3}\right) \mathrm{NC}(\mathrm{Me}) \mathrm{CHC}-(\mathrm{Me}) \mathrm{N}\right\}_{2}\right]$ (Scheme 2). Conversely, the octanuclear metal cluster $\left.\mathrm{PARA}_{3} \mathrm{Mg}_{8} \mathrm{H}_{10} \quad\left[\mathrm{PARA}=\left(2,6-{ }^{i} \mathrm{Pr}_{2} \mathrm{C}_{6} \mathrm{H}_{3}\right) \mathrm{NC}(\mathrm{Me}) \mathrm{C}(\mathrm{H}) \mathrm{C}(\mathrm{Me})-\mathrm{N}\right]_{2}-\left(p-\mathrm{C}_{6} \mathrm{H}_{4}\right)\right]$ provided 1,2- and 1,4-DHP dependent on temperature. However, catalytic hydroboration of pyridine derivatives in stoichiometric amount in presence of tetranuclear magnesium cluster could not transform into 1,2-regioselectivity.

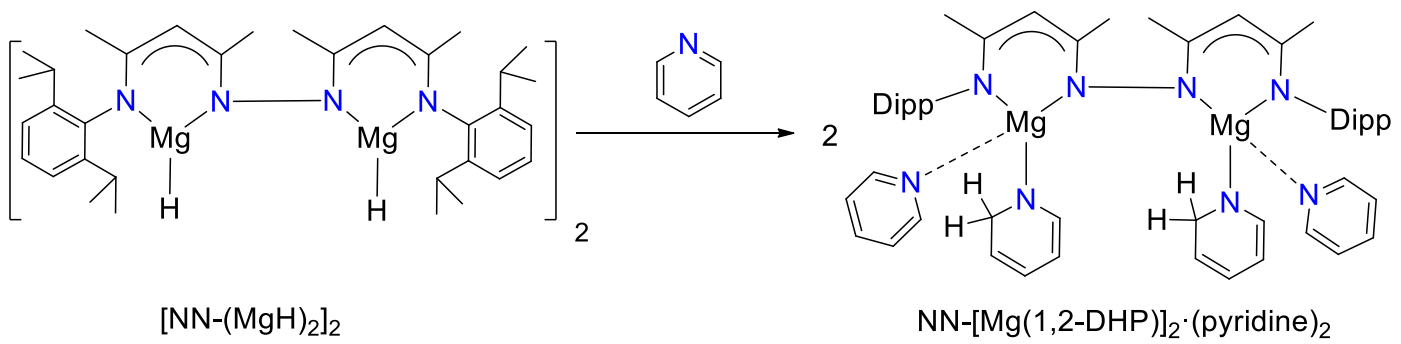

Scheme 2. 1,2-DHP selectivity of pyridine by $\left[\mathrm{NN}-(\mathrm{MgH})_{2}\right]_{2}$.

On a parallel note, the Sadow research group developed a magnesium complex $\mathbf{3}$ supported by tris(4,4-dimethyl-2-oxazolinyl)phenylborate ligand that effectively reduced esters via hydroboration as described in Scheme $3 .{ }^{54} \mathrm{~A}$ broad range of respective alkoxyboronic acids were achieved within 0.5-2 hours of the reaction time by utilizing 0.5-5 mol\% catalyst. Further kinetic studies were pursued to determine the mechanistic details, which proved the zwitterionic mechanism between magnesium and boron centers ruling out the classical $\sigma-$ bond metathesis pathway. Hill et al. also documented the kinetic analysis for rate determination of magnesiumcatalyzed $\mathbf{1}$ hydroboration of pyridines, isoquinoline, and dearomatization of poly-pyridines.$^{55}$
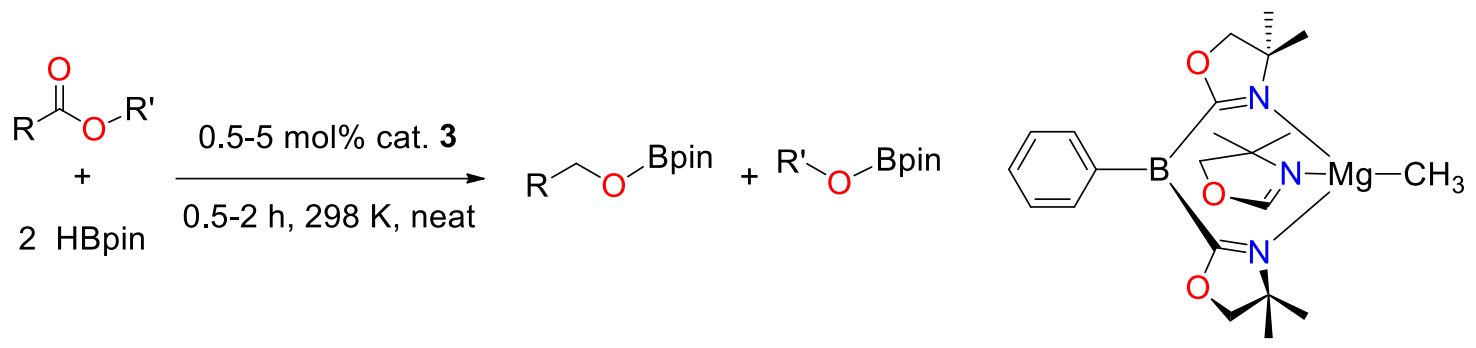

Scheme 3. Hydroboration of ester promoted by $\mathrm{Mg}(\mathrm{II})$ complex 3 . 


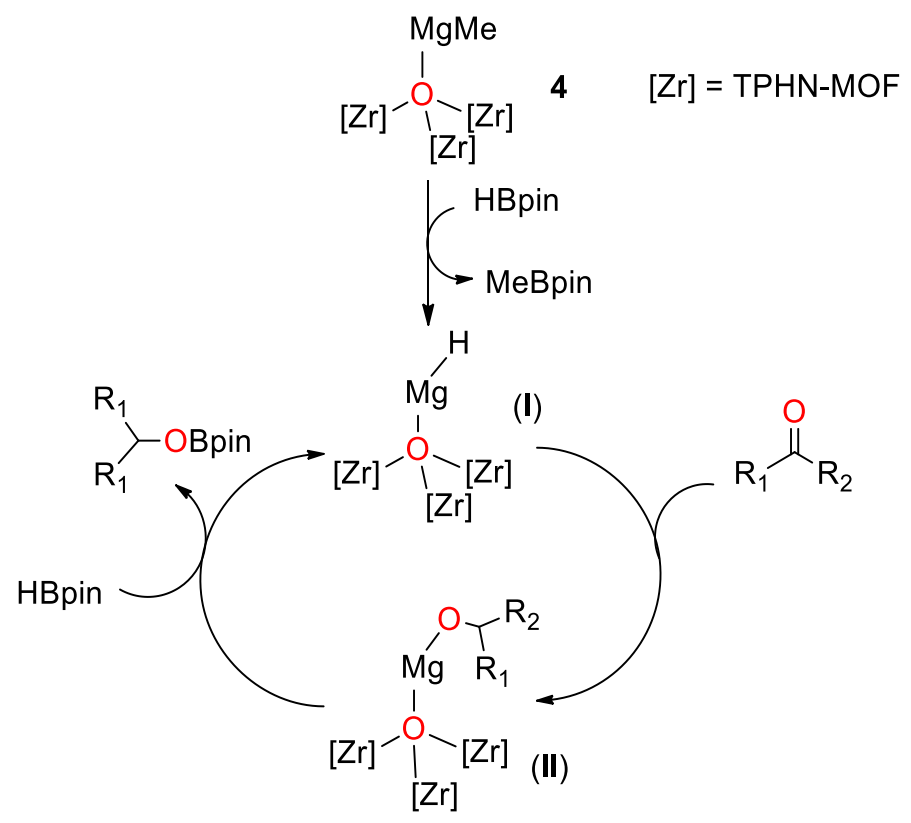

Scheme 4. The most plausible mechanism of TPHN-MOF-Mg-promoted hydroboration reaction.

Alongside, Lin and his team demonstrated a unique metal-organic framework supported magnesium alkyl complex namely TPHN-MOF (TPHN = 4,4'-bis-(carboxyphenyl)-2-nitro-1,1'biphenyl)-supported Mg-alkyl complex 4 as a single-site solid catalyst for the hydroboration of $\mathrm{C}=\mathrm{O}$ and $\mathrm{C}=\mathrm{N}$ derivatives as well as hydroamination of aminoalkanes. ${ }^{56 \mathrm{~b}}$ TPHN-MOF was formerly derived from the solvothermal reaction of $\mathrm{ZrCl}_{4}$ and $\mathrm{H}_{2} \mathrm{TPHN}$ in $\mathrm{DMF}$ and $\mathrm{CF}_{3} \mathrm{COOH}$ in excellent yield. ${ }^{56 a}$ The $\mathrm{Zr}-\mathrm{MOF}$ further reacted with $\mathrm{Me}_{2} \mathrm{Mg}$ at room temperature in THF to produce the desired catalyst TPHN-MOF-MgMe. High efficacy was exhibited by the catalyst for hydroboration of carbonyl compounds, imines and hydroamination of aminoalkenes in presence of very low catalyst loading 0.05-1 mol\%. Scheme 4 describes the most plausible mechanism for the TPHN-MOF-MgMe-catalyzed hydroboration reaction of carbonyl compounds. An active TPHN-MOF-Mg-H (I) species is generated onto which insertion of $\mathrm{C}=\mathrm{O}$ bond of the carbonyl substrates takes place producing $\mathrm{Zr}_{3}-\left(\mu_{4}-\mathrm{O}\right)-\mathrm{Mg}\left(\mathrm{OCHR}_{1} \mathrm{R}_{2}\right)$ intermediate (II) that finally affords the boronate ester product. 


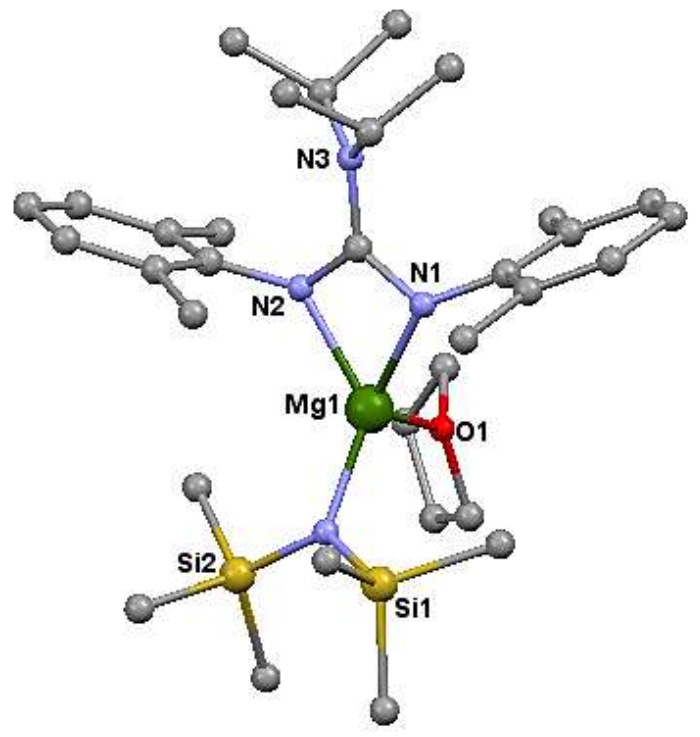

Figure 3. Molecular structure of $\mathrm{Mg}(\mathrm{II})$-guanidinate complex 5 in hydroboration of esters. Hydrogen atoms are omitted for clarity. CCDC No. 1506291. See Ref. 57.

Later, in 2017, a selective hydroboration methodology for a series of esters, promoted by bulky heteroleptic guanidinate-supported magnesium amide complexes 5-6, was reported by the Nembenna research group. ${ }^{57}$ The H-B addition onto ester was efficiently carried out by magnesium bis(trimethylsilyl)amide along with complexes 5 and 6. The molecular structure of the catalyst 5 has been shown in figure 3 . A very low catalyst loading of $0.1 \mathrm{~mol} \% \mathrm{Mg}\left[\mathrm{N}\left(\mathrm{SiMe}_{3}\right)_{2}\right]_{2}$ carried out the straightforward hydroboration of benzyl benzoate very smoothly. The isolation of possible reactive intermediates are feasible when steric moieties are being utilized. This urged the researchers to examine the reaction with the bulky complexes 5-6, which were also proficient in producing excellent yields of alkoxyboronate esters at mild conditions. Scheme 5 describes the reaction protocol and the most plausible mechanism that proceeds via magnesium hydride as the active catalyst for the reduction of a wide range of esters. High functional group tolerance has been achieved in presence of $\mathrm{Mg}\left[\mathrm{N}\left(\mathrm{SiMe}_{3}\right)_{2}\right]_{2}$ and $\mathbf{5}$. 


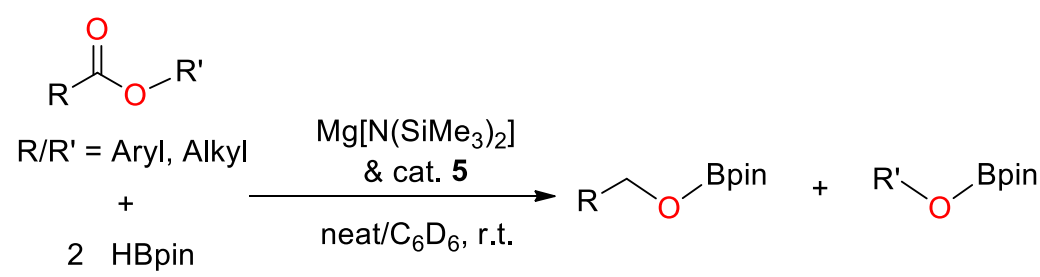

$\mathrm{LMg}-\mathrm{N}\left(\mathrm{SiMe}_{3}\right)_{2}$

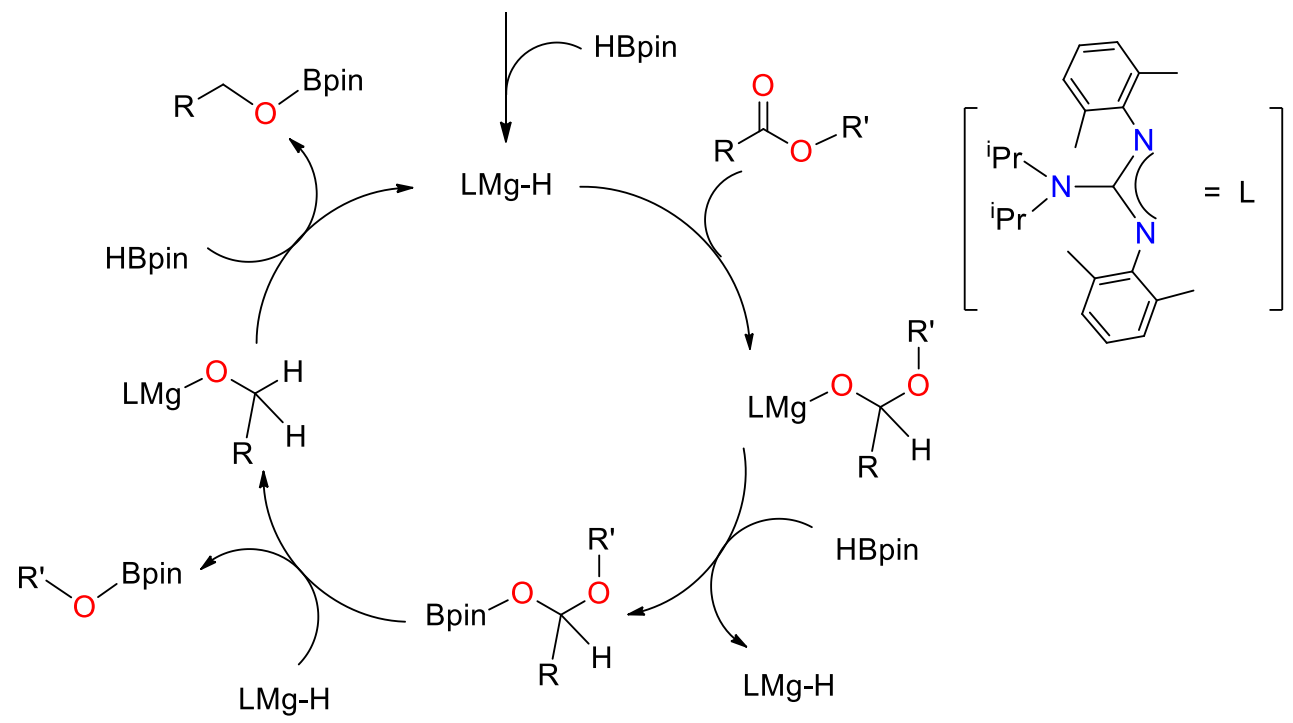

Scheme 5. $\mathrm{Mg}$ (II)-catalyzed hydroboration and reduction of esters and most plausible mechanism.

Sterically hindered secondary amidomagnesium methyl catalysts were developed by $\mathrm{Ma}$ and Pullarkat. The complexes provided corresponding boronate esters from the hydroboration of a range of aromatic and aliphatic ketones quite commendably. ${ }^{58}$ The $\mathrm{Mg}(\mathrm{II})$ complexes $\mathbf{7 - 1 0}$ were obtained by the reaction between secondary amines and the Grignard reagent (Scheme 6). The complexes 7-10 exhibited outstanding catalytic efficacy over reported $\operatorname{Mg}(\mathrm{II})$ catalyst 1 for the reduction of the ketone. Catalyst 10 required 30 minutes of reaction time to undergo hydroboration of acetophenone, however, catalysts 7-9 required prolonged reaction time to afford the product. This comparatively slow catalytic activity has been attributed to the structural steric bulk factor. Therefore, $0.1-1 \mathrm{~mol} \%$ of $\mathbf{1 0}$ was subjected for the catalytic hydroboration of ketones and quantitative yields of the products were achieved successfully at room temperature. Additionally, in 2018, the research group also established the first series of unsymmetrical $\beta$-diketiminate $\operatorname{Mg}(\mathrm{I})$ complexes 11-13 having confined Mg-Mg single bond. The catalysts were utilized toward the 
reduction of a range of alkynes, nitriles, aldehydes, and ketones (Scheme 7). ${ }^{59}$ Considering the steric factor of the ligand core, complex 12 was recognized as the suitable catalyst for the hydroboration of alkynes and carbonyl compounds. The aldehydes and ketones afforded the respective boronate esters at room temperature in presence of $0.1 \mathrm{~mol} \% \mathbf{1 2}$.<smiles>[R3][SiH2]Nc1c(C(c2ccccc2)c2ccccc2)cc([R])cc1C(c1ccccc1)c1ccccc1</smiles>

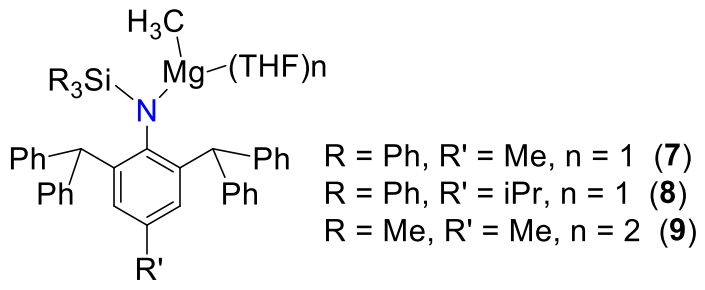<smiles>[R3][SiH2]Nc1c(C(C)C)cccc1C(C)(C)C</smiles><smiles>CC(C)(C)C(C)(C)C</smiles><smiles>CC(C)[SiH2]N([SiH2]C(F)F)c1c(C(C)C)cccc1C(C)C</smiles>

(10)
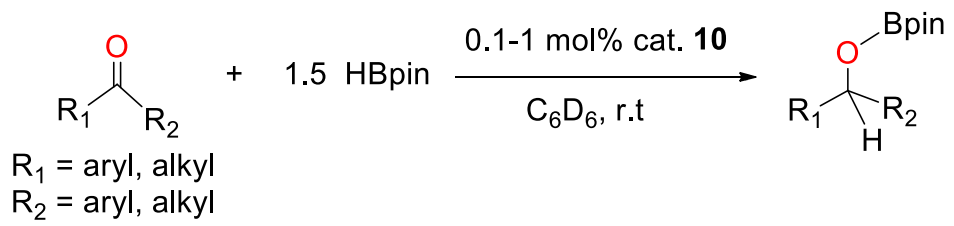

$\mathrm{R}_{1}=$ aryl, alkyl

$\mathrm{R}_{2}=$ aryl, alkyl

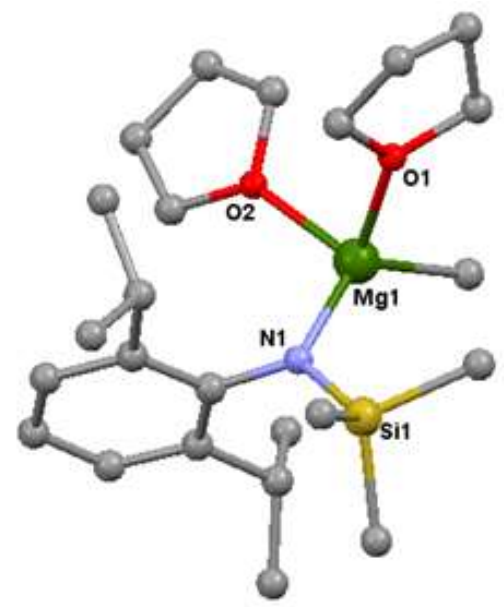

Scheme 6. Bulky secondary amidomagnesium methyl complexes 7-10 for hydroboration of ketones. The solid-state structure of $\mathrm{Mg}(\mathrm{II})$ catalyst 10. Hydrogen atoms are omitted for clarity. CCDC No. 1554846. See Ref. 58.

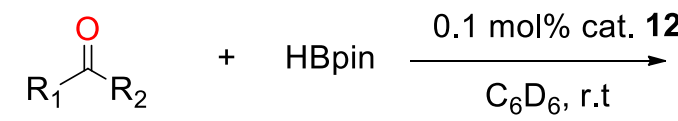

$$
\begin{aligned}
& \mathrm{R}_{1}=\text { aryl } \\
& \mathrm{R}_{2}=\mathrm{H} \text {, aryl, alkyl } \\
& \begin{array}{l}
\mathrm{R}_{1}=\mathrm{R}_{2}+1.5 \mathrm{HBpin} \underset{\mathrm{Tol}-\mathrm{d}_{8}, 110{ }^{\circ} \mathrm{C}}{\stackrel{5 \text { mol\% cat. } 12}{\longrightarrow}} \\
\mathrm{R}_{1}=\text { aryl } \\
\mathrm{R}_{2}=\mathrm{H}, \text { alkyl }
\end{array} \\
& \underset{R=\text { alkyl,aryl }}{R-C \equiv N}+2 \text { HBpin } \frac{10 \text { mol\% cat. } 11}{C_{6} D_{6}, 60^{\circ} \mathrm{C}}
\end{aligned}
$$<smiles>[R]C([R])O[B][Ba]</smiles><smiles>[R]C=C([R2])[Hg]Br</smiles><smiles>[R]CN([B])[B]</smiles>

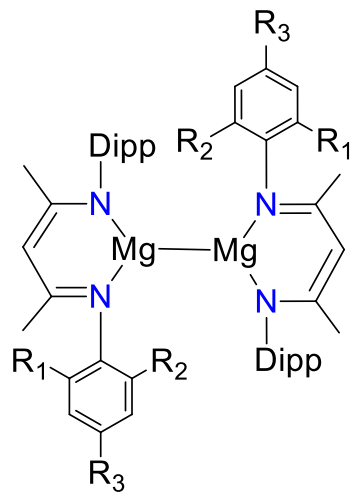

$R_{1}=R_{2}=R_{3}=M e$ (11)

$\mathrm{R}_{1}=\mathrm{R}_{2}=\mathrm{Me}, \mathrm{R}_{3}=\mathrm{H}$ (12)

$\mathrm{R}_{1}=\mathrm{R}_{3}=M e, \mathrm{R}_{2}=\mathrm{H}$ (13) 
Scheme 7. Unsymmetrical $\beta$-diketiminate $\operatorname{Mg}(\mathrm{I})$ complexes proficient in hydroboration of alkynes, nitriles, and carbonyl compounds.

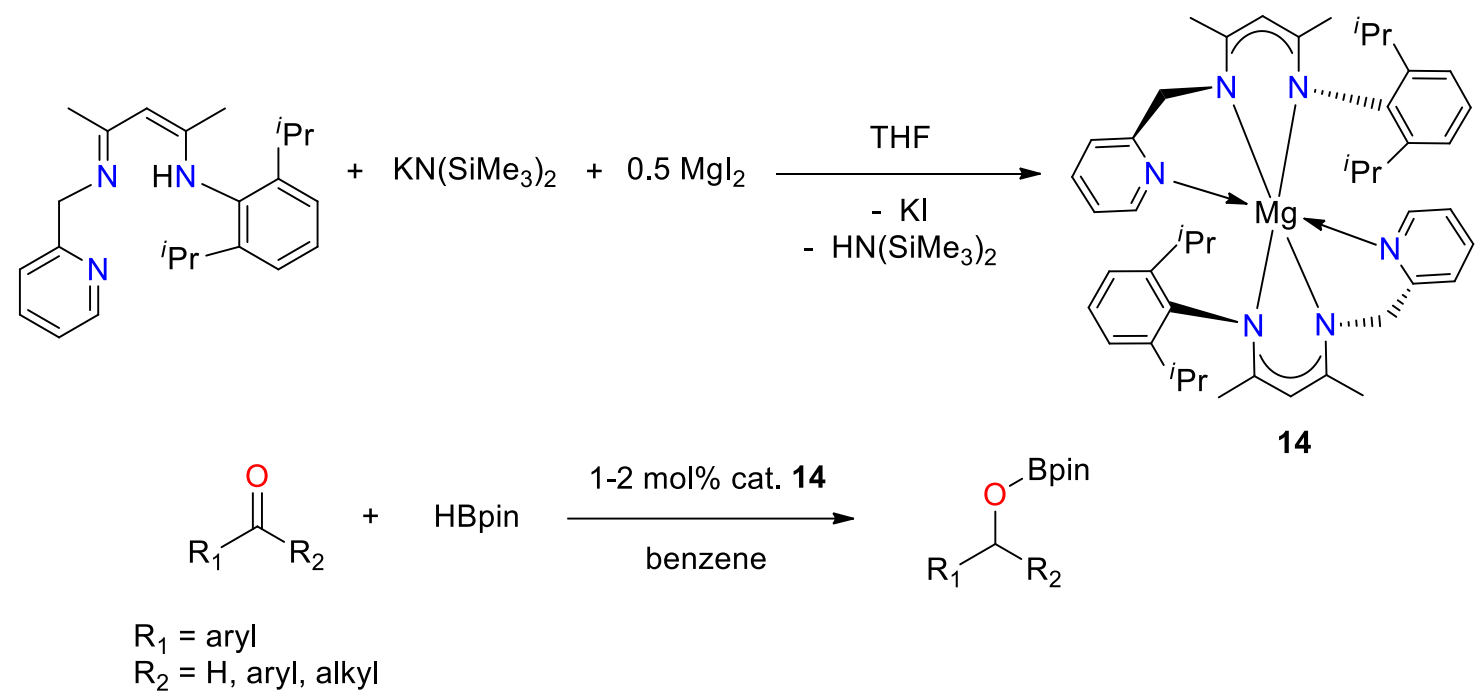

Scheme 8. Synthesis of $\operatorname{Mg}($ II) catalyst 14 utilized for catalytic hydroboration of carbonyl compounds.

Sen and coworkers developed homoleptic $\mathrm{Mg}$ (II) and $\mathrm{Ca}$ (II) metal complexes supported by tridentate $\beta$-diketiminato ligand connected by methyl-pyridine groups. The isolated molecular structure of $\mathrm{Mg}$ (II) complex 14 displays distorted octahedral geometry. Very low catalyst loading (1 mol\%) of the homoleptic complexes were highly efficient for hydroboration of carbonyl compounds under mild conditions. ${ }^{60}$ The schematic synthesis of complex $\mathbf{1 4}$ acquired by the reaction of the ligand $\mathrm{CH}_{3} \mathrm{C}\left(2,6-\left({ }^{i} \mathrm{Pr}\right)_{2} \mathrm{C}_{6} \mathrm{H}_{3} \mathrm{NH}\right) \mathrm{CHC}\left(\mathrm{CH}_{3}\right)\left(\mathrm{NCH}_{2}-\mathrm{C}_{5} \mathrm{NH}_{4}\right)$ with $\mathrm{K}\left(\mathrm{NSiMe}_{3}\right)_{2}$ and $\mathrm{MgI}_{2}$ has been demonstrated in scheme 8. A wide range of aldehydes and ketones underwent reduction in the presence of HBpin and corresponding products were achieved in excellent yields.

Rueping and his research group provided an alternative simple and innovative methodology for the enantioselective synthesis of alcohols by the reduction of carbonyl compounds by commercially available chiral magnesium complex. ${ }^{61}$ Excellent yields and enantioselectivities for a variety of ketones undergoing $\mathrm{MgBu}_{2}$-catalyzed asymmetric hydroboration in the presence of HBpin and chiral $(R)-(+)$-BINOL ligand were obtained. Computational studies established that the reaction proceeds via the formation of magnesiumligand cooperativity and the BINOL ligand act as a non-innocent ligand. Scheme 9 sets out the catalytic reaction methodology along with the pathway for cooperative catalysis. 
See the original article: Applied Organometallic Chemistry, 2021, Doi: 10.1002/aoc.6333

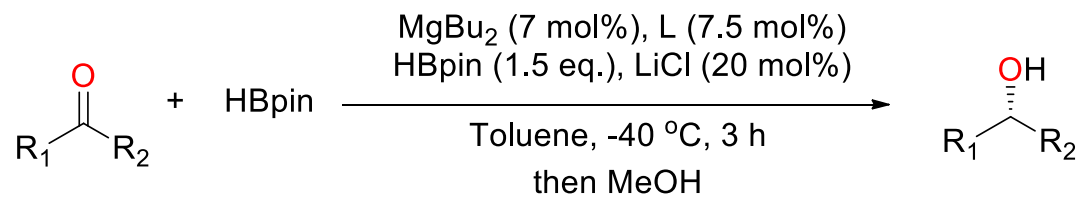<smiles>OCCCCOCCO</smiles>

$\mathrm{L}$

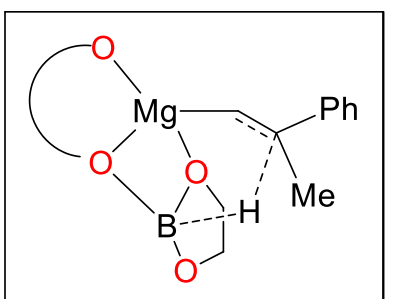

cooperative activation

Scheme 9. Asymmetric magnesium-catalyzed hydroboration of ketones.

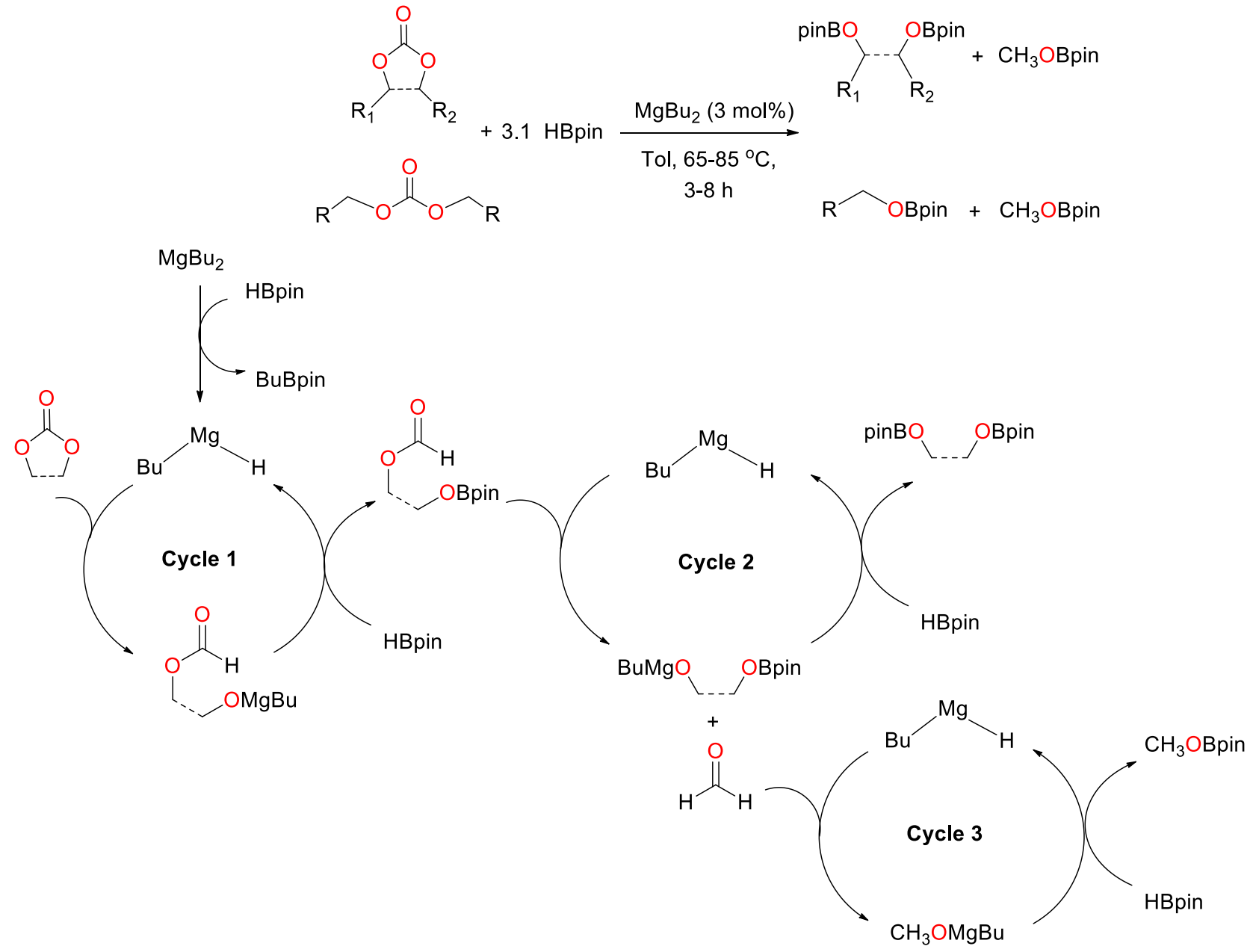


Scheme 10. $\mathrm{MgBu}_{2}$-catalyzed reduction of cyclic and linear carbonates. The most plausible mechanism of sequential reduction of carbonates.

Additionally, the efficacy of the same catalyst was tested for the reduction of cyclic and linear carbonates. $\mathrm{MgBu}_{2}$ mediated reduction of several carbonates was carried out in presence of 3.1 equivalents of HBpin (Scheme 10). ${ }^{62}$ Predictably, double hydroboration was observed in challenging cyclic carbonates and excellent yields of the diboronate esters were acquired. Notably, symmetrical linear carbonates demanded higher reaction conditions and selectively single hydroboration occurred producing mono-boronate esters with 92-95\% yield. The proposed mechanism has been displayed in Scheme 10 that demonstrates the active $\mathrm{Mg}-\mathrm{H}$ catalyst is associated sequentially with three reduction cycles. The research group continued their study toward the development of $\mathrm{MgBu}_{2}$ as a versatile commercial catalyst system. $0.2-0.5 \mathrm{~mol} \%$ of the catalyst aided chemoselective reduction of $\alpha, \beta$-unsaturated ketones and excellent yields were achieved using pinacolborane under ambient conditions. ${ }^{63}$ Besides, successful reduction of a number of enones and propargylic ketones were achieved. Scheme 11 sets forth the proposed mechanism for the formation of an active $\mathrm{Mg}-\mathrm{H}$ complex followed by the sequential catalytic cycle.

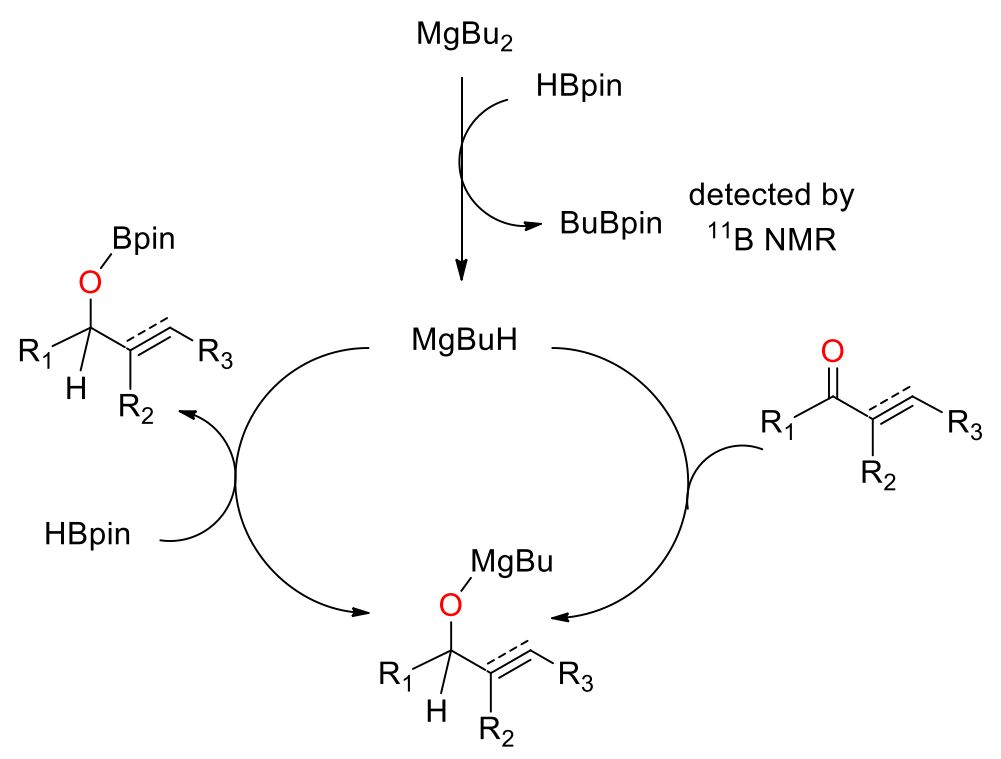

Scheme 11. $\mathrm{MgBu}_{2}$-catalyzed chemoselective hydroboration of $\alpha, \beta$-unsaturated ketones.

Computational studies for the determination of mechanistic details have gained remarkable attention among many research groups. In a very recent study on DFT calculations, the mechanism 
for hydroboration of pyridines with boranes mediated by alkaline-earth metal catalysts was detemined ${ }^{64}$ The theoretical calculations were influenced by the previous report of hydroboration of pyridines by the Harder research group and this study validated their mechanistic pathway. ${ }^{53}$ As investigated from the DFT calculations, $\mathrm{Mg}-\mathrm{H}$ intermediate forms the active pre-catalyst that aids dearomatization of pyridine moieties. The trend of the bond dissociation energies of the Ae complexes has been observed as $\mathrm{Mg}-\mathrm{H}>\mathrm{Ca}-\mathrm{H}>\mathrm{Sr}-\mathrm{H}$. Quite recently, $\mathrm{MgBu}_{2}$ was furthermore employed for the hydroboration of linear and cyclic carbamates. ${ }^{65} 3.5$ equivalents of HBpin in presence of $10 \mathrm{~mol} \% \mathrm{MgBu}_{2}$ under neat and mild reaction conditions afforded a library of $\mathrm{N}$ methyl amines in good to excellent yields using as represented in scheme 12a. Additionally, Dincorporation to the carbamates using DBpin was also performed as the corresponding $\mathrm{N}$ trideuteromethylated products are valuable metabolic and pharmacokinetic substrates (Scheme $12 b)$.

(a)

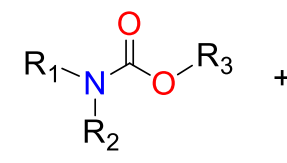

$\mathrm{R}_{1}=$ aryl, alkyl

$\mathrm{R}_{2}=$ aryl, alkyl

$\mathrm{R}_{3}=\mathrm{alkyl}$

(b)

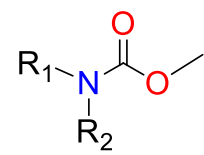

$\mathrm{R}_{1}=$ aryl

$\mathrm{R}_{2}=\mathrm{H}$, alkyl

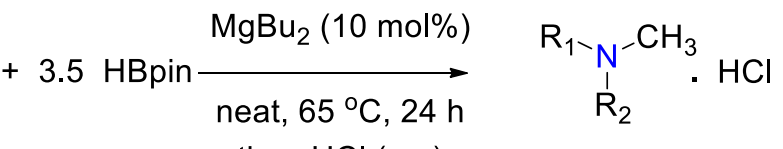

then $\mathrm{HCl}$ (aq.)

$\mathrm{MgBu}_{2}(10 \mathrm{~mol} \%)$

neat, $80^{\circ} \mathrm{C}, 24 \mathrm{~h}$

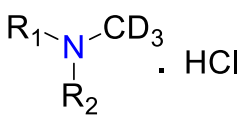

Scheme 12. Reduction of carbamates mediated by $\mathrm{MgBu}_{2}$.

$\mathrm{Ma}$ and coworkers also advanced their research with magnesium metal catalysts and established highly efficient low-valent $\mathrm{Mg}(\mathrm{I})$ metal complex for catalytic hydroboration of several organic carbonates, esters, and $\mathrm{CO}_{2} \cdot{ }^{66} 1 \mathrm{~mol} \%$ of $\beta$-diketiminato supported $\mathrm{Mg}(\mathrm{I})$ complex 15 having $\mathrm{Mg}-\mathrm{Mg}$ bond alike with the metal complexes 11-13 proved as effective for the reduction of carbonates and esters with HBpin under the neat condition at room temperature (Scheme 13). The research group also applied simple, low-cost, and readily accessible Grignard reagent for the reduction of carbonyl compounds efficiently. Low catalyst loading of $\mathrm{MeMgI}$ at room temperature and neat condition efficiently carried out hydroboration reactions of aldehydes and ketones within 
10-20 minutes of reaction time. ${ }^{67}$ Chemoselectivity of the Grignard reagent toward hydroboration of aldehydes over ketones were examined. Additionally, DFT calculations also assisted the possible pathway for the reaction mechanism and the thermodynamic and kinetic feasibility according to the experimental conditions.

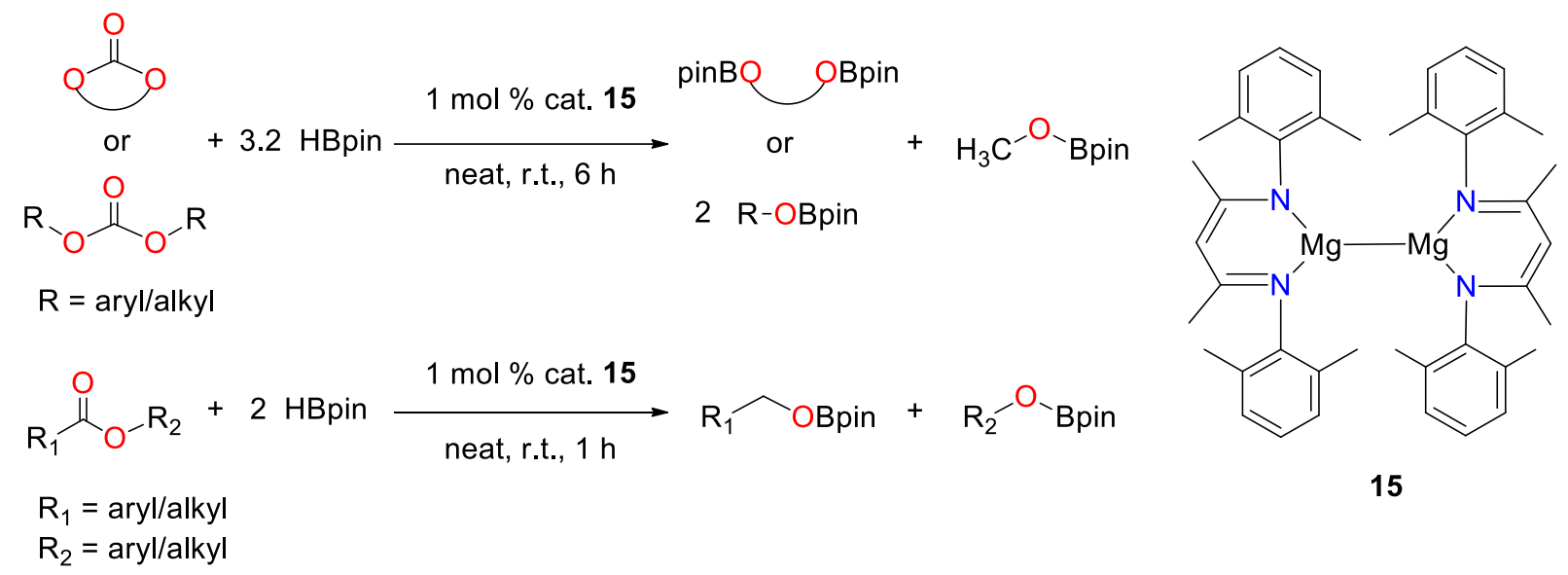

Scheme 13. $\operatorname{Mg}(\mathrm{I})$ catalyst 15 efficient for the reduction of organic carbonates and esters.

The Gade research group during the same time modified and developed in situ bis(oxazolinyl-methylidene)isoindoline magnesium alkyl complexes. The use of $5 \mathrm{~mol} \%$ each of boxmi-H ligand with $\left[\mathrm{Mg}\left(\mathrm{CH}_{2} \mathrm{SiMe}_{3}\right)_{2} \mathrm{THF}\right]$ executed the reduction of ketones successfully via hydroboration and the respective alcohol derivatives were achieved with high enantioselectivities. ${ }^{68}$ DFT calculations recognized the formation of magnesium borohydride intermediate from the reaction of magnesium hydride and pinacolborane.

\subsection{Hydroelementation reactions of $\mathrm{CO}_{2} / \mathrm{CO}$.}

Hill et al. in 2014 reported the catalytic activity of the alkaline earth-hydride complexes 16-17 modified by tris(pentafluorophenyl)borane Lewis acid. The modified metal pre-catalysts were noted as highly selective metal complexes for the reduction of $\mathrm{CO}_{2}{ }^{69}$ The complex $\mathbf{1 6}$ was further reacted under $\mathrm{CO}_{2}(1 \mathrm{~atm}$.) to produce a new metal complex 18 well-characterized by spectroscopic techniques. The catalytic hydroboration of $\mathrm{CO}_{2}$ was successfully employed by using 3 equivalents of pinacolborane in the presence of $10 \mathrm{~mol} \%$ of the metal catalysts 16-18 (Scheme 14). The characterization of $\mathrm{CH}_{3} \mathrm{OB}$ in was confirmed from NMR spectroscopy. 

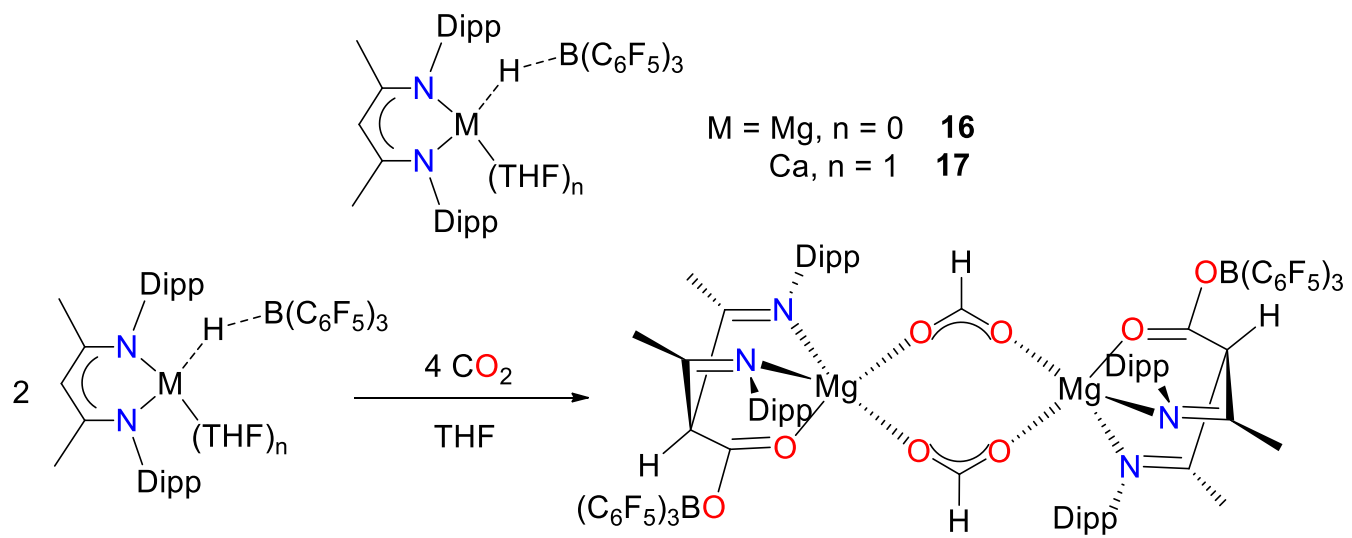

16

18
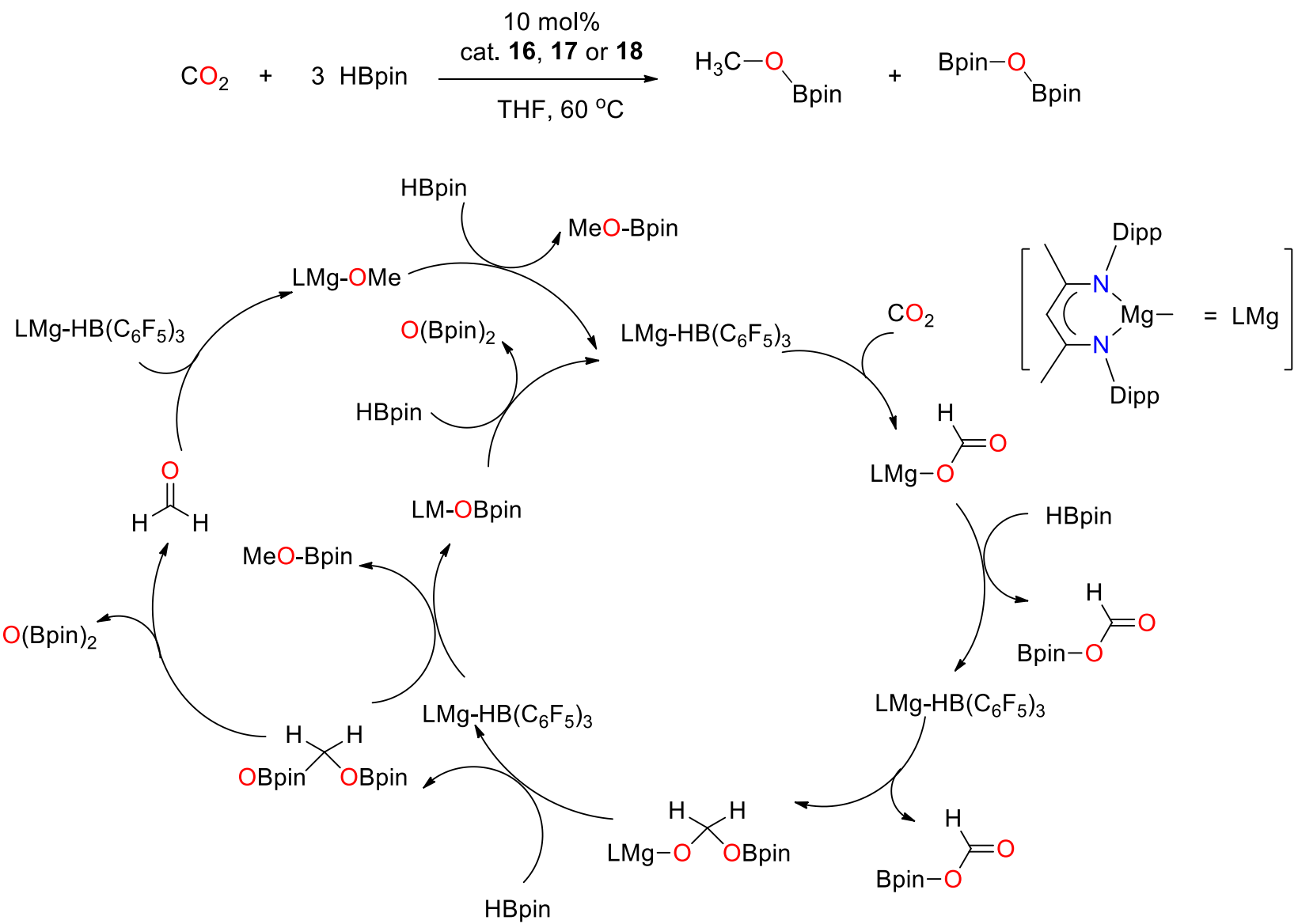

Scheme 14. Modified $\mathrm{Mg}(\mathrm{II})$ complexes promoted the reduction of $\mathrm{CO}_{2}$. The proposed mechanistic pathway for hydroboration of $\mathrm{CO}_{2}$.

Hill's research group previously published the hydroboration of carbonyl compounds that proceeded through heteroleptic $\mathrm{Mg}-\mathrm{H}$ as the active intermediate. ${ }^{52}$ The readily accessible $\mathrm{Mg}-\mathrm{H}$ 
complex 2 was employed for the reduction of carbon monoxide. ${ }^{70}$ Catalytic deoxygenative reduction of $\mathrm{CO}$ was observed producing cis-enediolate species. Catalytic hydrosilylation was also achieved with phenylsilane postulated by the cleavage of $\mathrm{C} \equiv \mathrm{O}$ bond and the formation of the magnesium formyl intermediate. A year later, Okuda and his team demonstrated the hydroboration of a series of unsaturated compounds including $\mathrm{CO}_{2}$ promoted by the magnesium bis(hydridridotriphenylborate) complex. ${ }^{71}$ The use of $0.01-1 \mathrm{~mol} \%$ of complex $\left[\mathrm{Mg}(\text { thf })_{6}\right]\left[\mathrm{HBPh}_{3}\right]_{2}$ effectively catalyzed the reduction of ketones and pyridine and the respective boronic ester and $\mathrm{N}$-borylated 1,4-dihydropyridine were achieved. The hydroboration reaction of ketones was carried out in DMSO, due to insolubility in THF, and a considerable amount of DMSO reduction was noticed. This motivated the researchers to investigate the catalytic deoxygenation of sulfoxides in presence of $\left[\mathrm{Mg}(\mathrm{thf})_{6}\right]\left[\mathrm{HBPh}_{3}\right]_{2}$, and the corresponding sulfides were observed along with $\mathrm{O}(\mathrm{Bpin})_{2}$ and $\mathrm{H}_{2}$ as the by-products (Scheme 15).

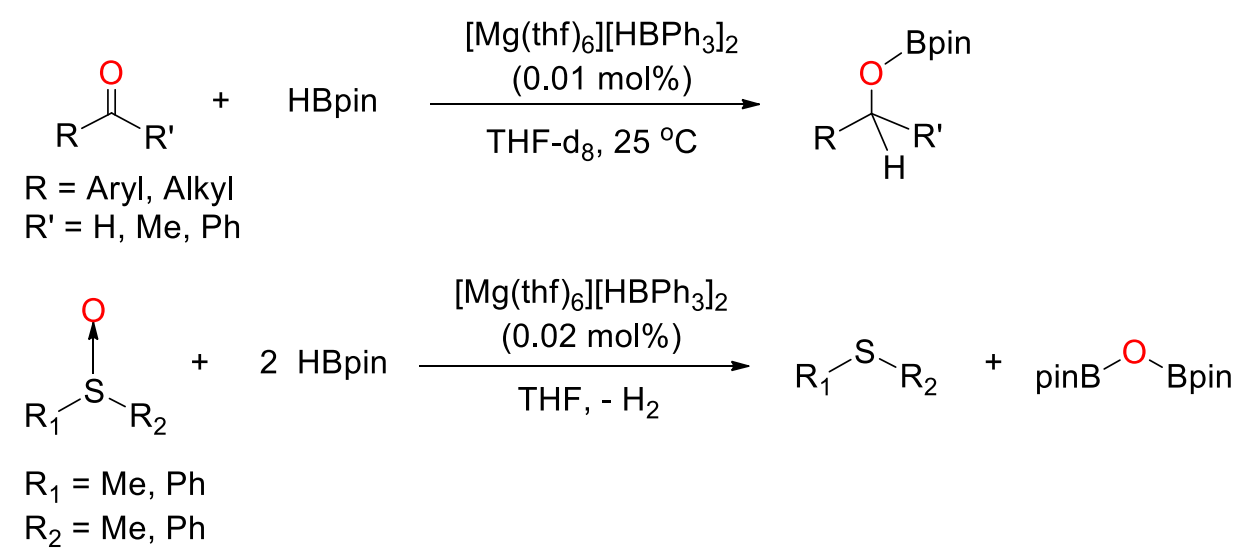

Scheme 15. Reduction of ketones and deoxygenation of sulfoxides catalyzed by $\left[\mathrm{Mg}(\text { thf })_{6}\right]\left[\mathrm{HBPh}_{3}\right]_{2}$.

The active catalyst was synthesized in high yield by the reaction of $\left[\mathrm{Mg}\left\{\mathrm{N}\left(\mathrm{SiHMe}_{2}\right)_{2}\right\}_{2}\right]$ with two equivalents of $\mathrm{BPh}_{3}$ under ambient conditions. Rapid reactivity of the catalyst was additionally accomplished with carbon dioxide. The insertion of $\mathrm{CO}_{2}$ into the $\mathrm{B}-\mathrm{H}$ bonds produced a new magnesium bis(formoxytriphenylborate) complex $\left[\mathrm{Mg}\left(\mathrm{HCO}_{2} \mathrm{BPh}_{3}\right)_{2}(\text { thf })_{4}\right]$ in quantitative yield (Figure 4). 


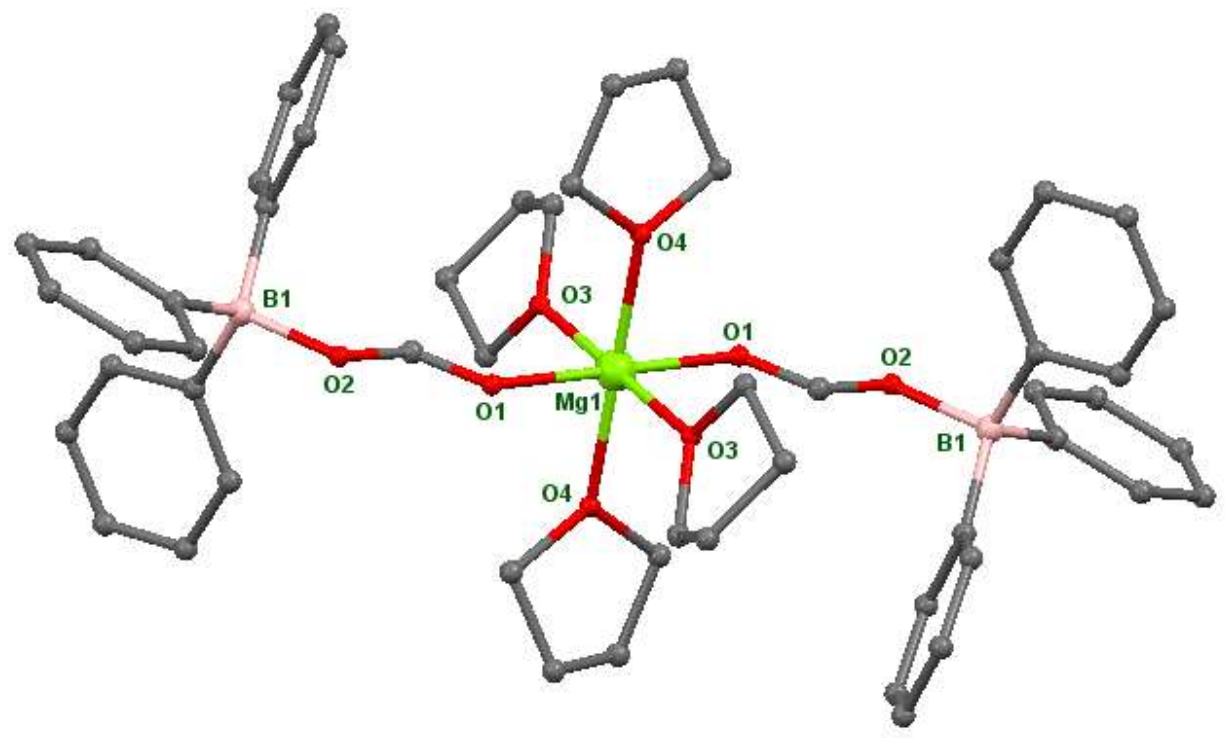

Figure 4. The molecular structure of $\left[\mathrm{Mg}\left(\mathrm{HCO}_{2} \mathrm{BPh}_{3}\right)_{2}(\text { thf })_{4}\right]$. Hydrogen atoms are omitted for clarity. CCDC No. 1498969. See Ref. 71.

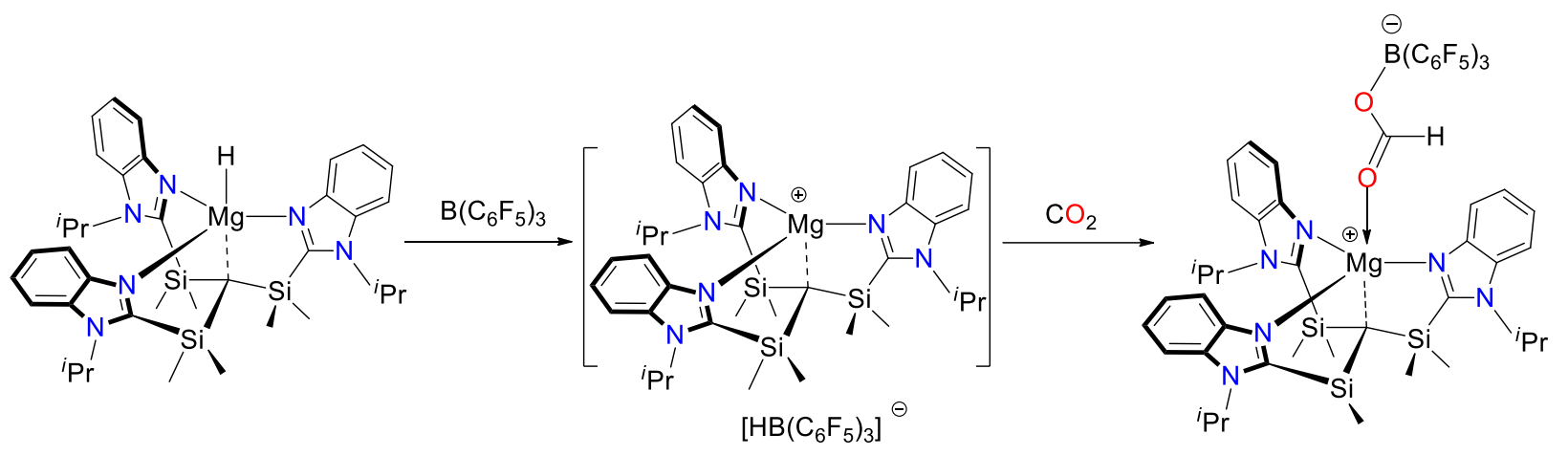

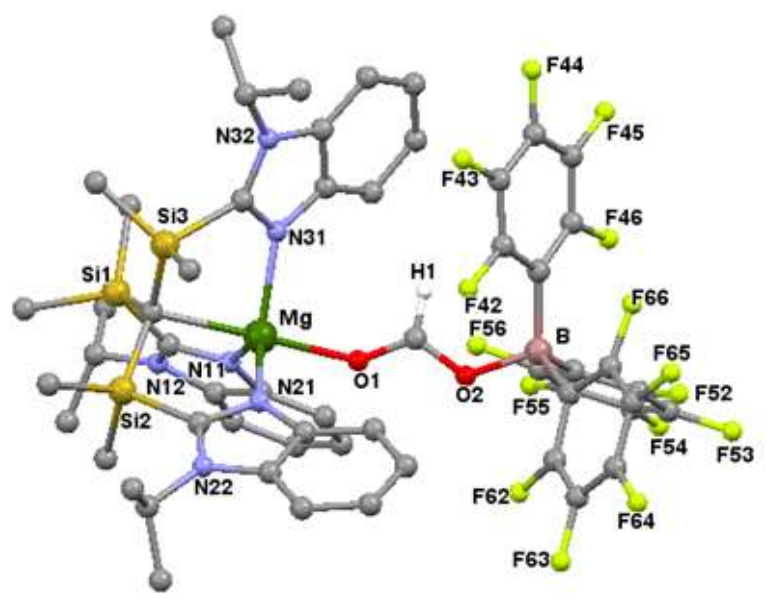




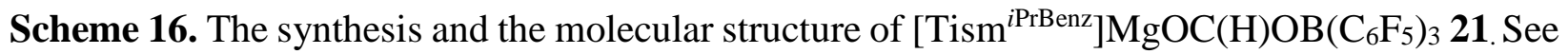
Ref. 72.

In another reaction methodology developed by Parkin, a catalyst [Tism $\left.{ }^{i{ }^{P B R e n z}}\right] \mathrm{MgH} 19$ was utilized for additional hydrofunctionalization reactions. ${ }^{79}$ Complex 19 when reacted with $\mathrm{B}\left(\mathrm{C}_{6} \mathrm{~F}_{5}\right)_{3}$, formed $\left\{\left[\mathrm{Tism}^{i \mathrm{PrBenz}}\right] \mathrm{Mg}\right\}\left[\mathrm{HB}\left(\mathrm{C}_{6} \mathrm{~F}_{5}\right)_{3}\right]$ 20. The catalytic system thus generated experienced hydrosilylation of $\mathrm{CO}_{2}$ by $\mathrm{R}_{3} \mathrm{SiH}$ efficiently at room temperature. ${ }^{72}$ Notably, the selectivity of this protocol was demonstrated by controlling the variation of silanes. The reaction of $\mathrm{CO}_{2}$ with $\mathrm{PhSiH}_{3}$ selectively afforded $\mathrm{CH}_{4}$, while $\mathrm{Ph}_{3} \mathrm{SiH}$ formed $\mathrm{H}_{2} \mathrm{C}\left(\mathrm{OSiPh}_{3}\right)_{2}$. The isolated single-crystal structure of magnesium formatoborate complex [Tism $\left.{ }^{i \mathrm{PrBenz}}\right] \mathrm{Mg}-\mathrm{OC}(\mathrm{H}) \mathrm{OB}\left(\mathrm{C}_{6} \mathrm{~F}_{5}\right)_{3} \mathbf{2 1}$ obtained from the reaction of complex $\mathbf{2 0}$ with $\mathrm{CO}_{2}$ is provided in Scheme 16.

A previous discussion described that $\mathrm{Ma}$ and coworkers established $\mathrm{Mg}(\mathrm{I})$ metal complex 15 for the reduction of $\mathrm{CO}_{2}$ along with several organic carbonates and esters. ${ }^{66}$ Nonetheless, an elevated temperature of $100{ }^{\circ} \mathrm{C}$ for 15 hours with 5 mol\% of $\mathbf{1 5}$ was necessary for the hydroboration of carbon dioxide as displayed in Scheme 17.

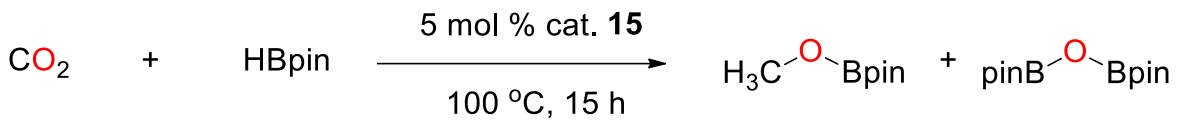

Scheme 17. Reduction of $\mathrm{CO}_{2}$ mediated by $\mathrm{Mg}(\mathrm{I})$ catalyst 15 .

\subsection{Hydroelementation reactions of alkynes.}

Formerly, Ma et al. established the $\beta$-diketiminate $\operatorname{Mg}(\mathrm{I})$ 11-13 complexes and employed them for the reduction of carbonyl compounds. The complexes also executed hydroboration of a range of alkynes quite efficiently. $5 \mathrm{~mol} \%$ catalyst 12 produced cis-alkenyl boronate esters by applying higher reaction temperature (Scheme 7). ${ }^{59}$ In 2019, the Rueping research group documented extensive studies on magnesium complexes proficient in the reduction of various unsaturated compounds. The group reported a competent and commercially available $\operatorname{Mg}\left(\mathrm{NTf}_{2}\right)_{2}$ catalyzed protocol for ortho-alkenylation of anilines using hexafluoroisopropanol (HFIP) as a solvent (Scheme 18). ${ }^{73}$ The catalyst acts as the Lewis acid and good tolerance for a range of alkynes and anilines were observed. For a deeper understanding of the catalytic reaction, deuterium labeling experiments were carried out. The proposed mechanism for ortho-alkenylation of anilines 
mediated by $\operatorname{Mg}\left(\mathrm{NTf}_{2}\right)_{2}$ also has been set out in Scheme 18. HFIP solvent is crucial that adds to $\mathrm{Mg}\left(\mathrm{NTf}_{2}\right)_{2}$ producing the active $\mathrm{Mg}(\mathrm{II})$-HFIP intermediate.

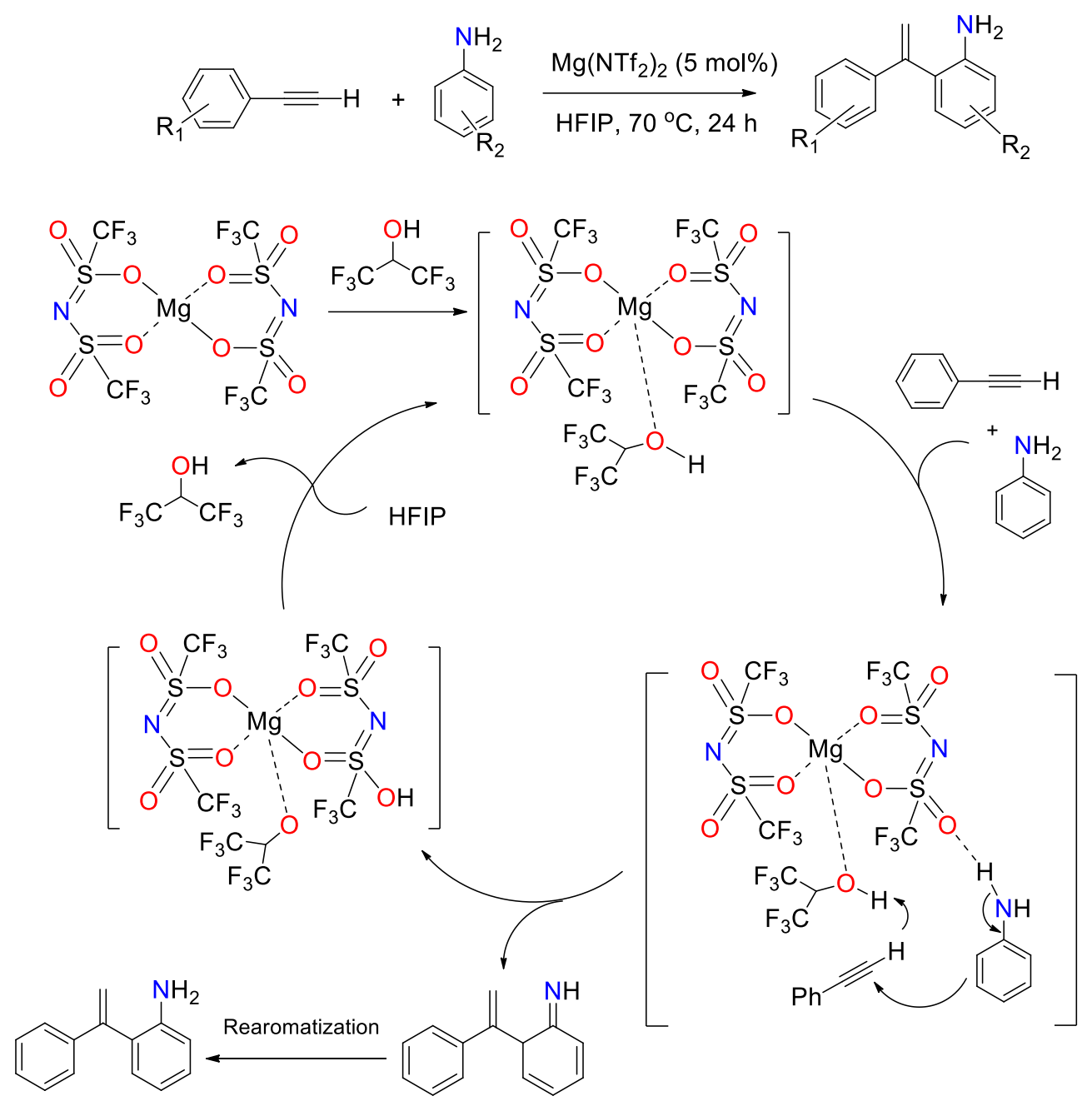

Scheme 18. $\operatorname{Mg}\left(\mathrm{NTf}_{2}\right)_{2}$ catalyzed ortho-alkenylation of anilines with the plausible mechanism.

Additionally, the same catalyst $\mathrm{MgBu}_{2}$ served for hydroboration reactions selectively toward the terminal and internal alkynes. ${ }^{74}$ DFT calculations provided the most favored mechanistic pathway, which proved the formation of $\mathrm{BuMgH}$ from the reaction between $\mathrm{MgBu}_{2}$ and $\mathrm{HBpin}$ based on the relative free energies of the intermediates (Scheme 19). The corresponding alkenyl boronate esters were achieved in good yields and selectivity under preferred conditions. 

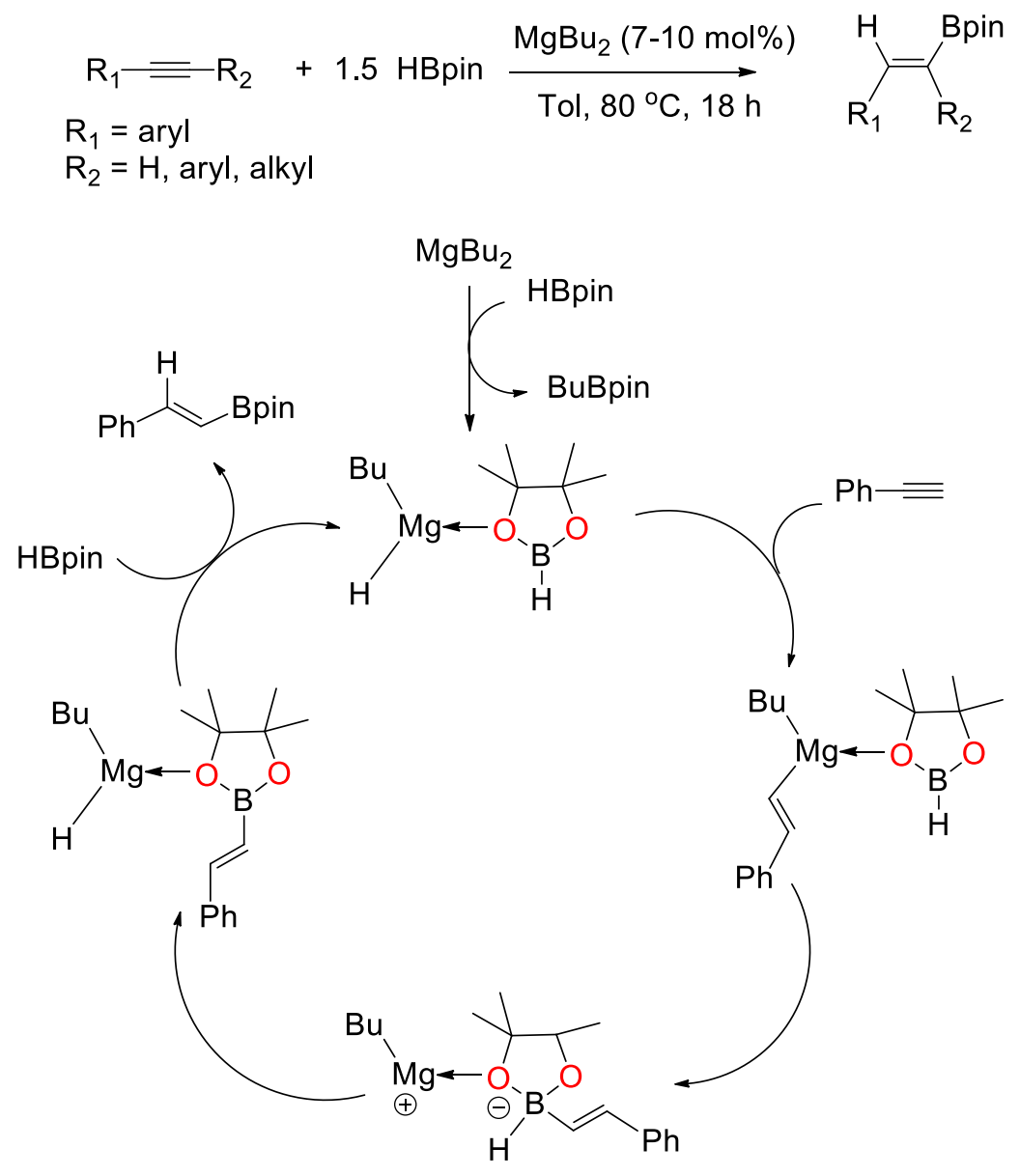

Scheme 19. $\mathrm{MgBu}_{2}$-catalyzed reduction of internal and terminal alkynes. The most favored mechanism.

In the same year, Hevia et al. documented systematic studies of alkali metal magnesiates as competent heterobimetallic catalysts for the hydroamination of alkynes and styrenes with variation in amines. ${ }^{75}$ The initial reaction of diphenylacetylene with piperidine in the presence of sodium magnesiate $\mathrm{NaMg}\left(\mathrm{CH}_{2} \mathrm{SiMe}_{3}\right)_{3}$ produced hydroamination product in excellent yield and high $E: Z$ selectivity. Additionally, higher-order variants of homoleptic triorganomagnesiates were examined and the catalytic hydroamination of alkynes and styrenes using [(PMDETA $\left.)_{2} \mathrm{~K}_{2} \mathrm{Mg}\left(\mathrm{CH}_{2} \mathrm{SiMe}_{3}\right)_{4}\right]$ verfied best results. Scheme 20 displays the heterobimetallic catalysts and the hydroamination reactions of diphenylacetylene and styrene. 


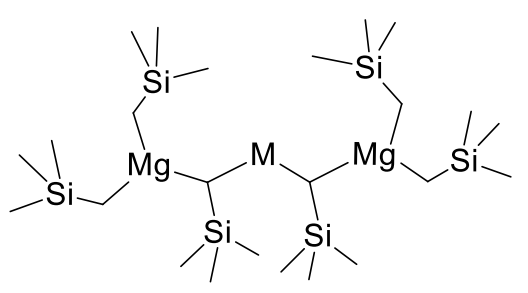

$\mathrm{M}=\mathrm{Li}, \mathrm{Na}, \mathrm{K}$<smiles>[R2]N([R])/C=C\c1ccccc1</smiles>

(E)

$+$<smiles>[R20]/C(P)=C/c1ccccc1</smiles>

(Z)

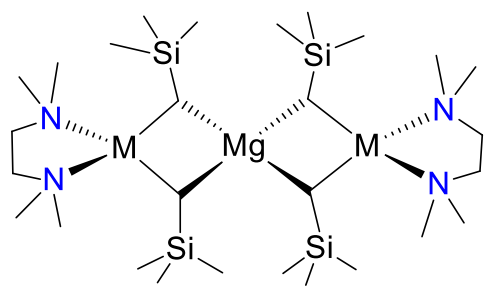

$\mathrm{M}=\mathrm{Li}, \mathrm{Na}$

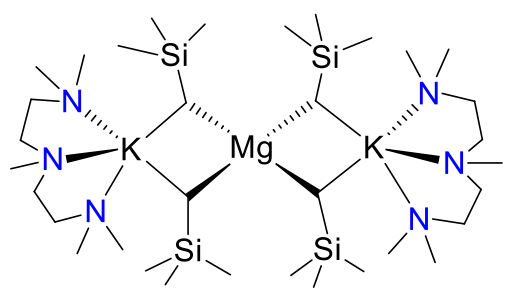

$\left[(\mathrm{PMDETA})_{2} \mathrm{~K}_{2} \mathrm{Mg}\left(\mathrm{CH}_{2} \mathrm{SiMe}_{3}\right)_{4}\right]$

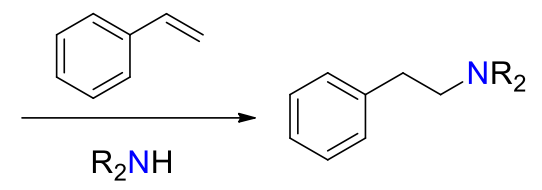

d8-THF, r.t. 15 mins

Scheme 20. Heterobimetallic catalysts mediated hydroamination reactions of diphenylacetylene and styrene.

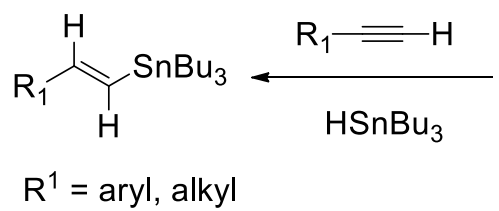

$\mathrm{R}^{1}=$ aryl, alkyl

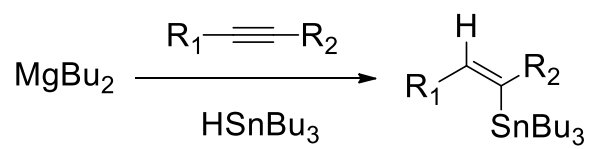

$\mathrm{R}^{1}=$ aryl, alkyl

$\mathrm{R}^{2}=$ alkyl

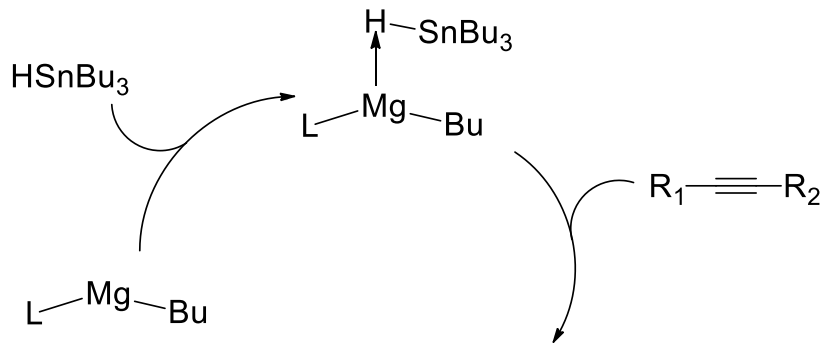

$\overbrace{\mathrm{SnBu}_{3}}^{\mathrm{R}_{2}}$

(a) $\mathrm{Mg}(\mathrm{II})$-activation of $\mathrm{H}-\mathrm{Sn}$ bond

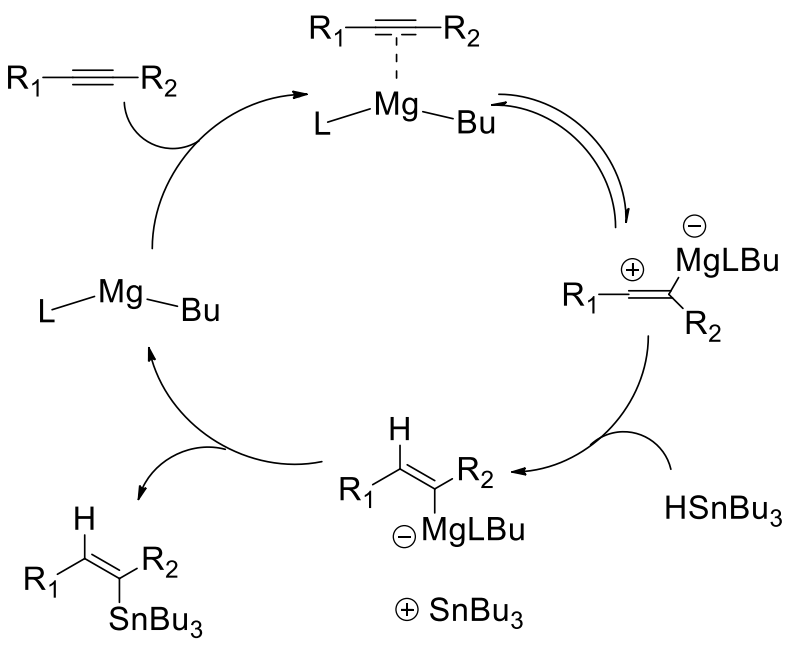

(b) $\mathrm{Mg}(\mathrm{II})$-activation of $\mathrm{C} \equiv \mathrm{C}$ bond

Scheme 21. $\mathrm{MgBu}_{2}$-catalyzed hydrostannylation of terminal and internal alkynes. 
Very interestingly, $\mathrm{MgBu}_{2}$ metal precursor was also noticed as a potent catalyst for the first report on hydrostannylation of a series of alkynes. ${ }^{76}$ The terminal and internal alkynes provided excellent yields with regio- and stereo-selectivities. Scheme 21 depicts $10 \mathrm{~mol} \% \mathrm{Mg}$ (II) catalyst promoted the addition of $\mathrm{HSnBu}_{3}$ to the internal alkynes that achieved (Z)-vinylstannes, while that of terminal alkynes achieved (E)-vinylstannes. The proposed mechanism suggested the hydrostannylation reaction proceeded either by the Lewis acid activation of $\mathrm{HSnBu}_{3}$ pathway or $\mathrm{C} \equiv \mathrm{C}$ bond as shown in Scheme 21.

\subsection{Hydroelementation reactions of nitriles.}

The reduction of the $\mathrm{C} \equiv \mathrm{N}$ group of organic nitriles into primary amines has been attracting researchers around the globe. Hill et al. advanced their research work with $\operatorname{Mg}(\mathrm{II})$ complex 1 and reported the first reduction of organic isonitriles. ${ }^{77}$ The use of $5 \mathrm{~mol} \% \beta$-diketiminato-derived magnesium alkyl catalyst under mild reaction conditions was highly efficient for the catalytic hydroboration of isonitriles and the corresponding 1,2-diborylated amines were acquired in excellent yield up to $99 \%$. Scheme 22 describes the proposed mechanism that generates the active $\mathrm{Mg}-\mathrm{H}$ catalyst and the insertion of isonitrile takes place. Catalyst $\mathbf{1}$ further proved to be an effective pre-catalyst for the hydroboration of organic nitriles with pinacolborane (HBpin) ${ }^{78}$ The catalytic reaction was performed using $10 \mathrm{~mol} \%$ metal complex with one equivalent of nitrile substrates and two equivalents of HBpin. The resultant 1,1-bis(boryl)amine product was obtained within 30 minutes to 13.5 hours when the reaction mixture was heated under ambient conditions (Scheme 23). 


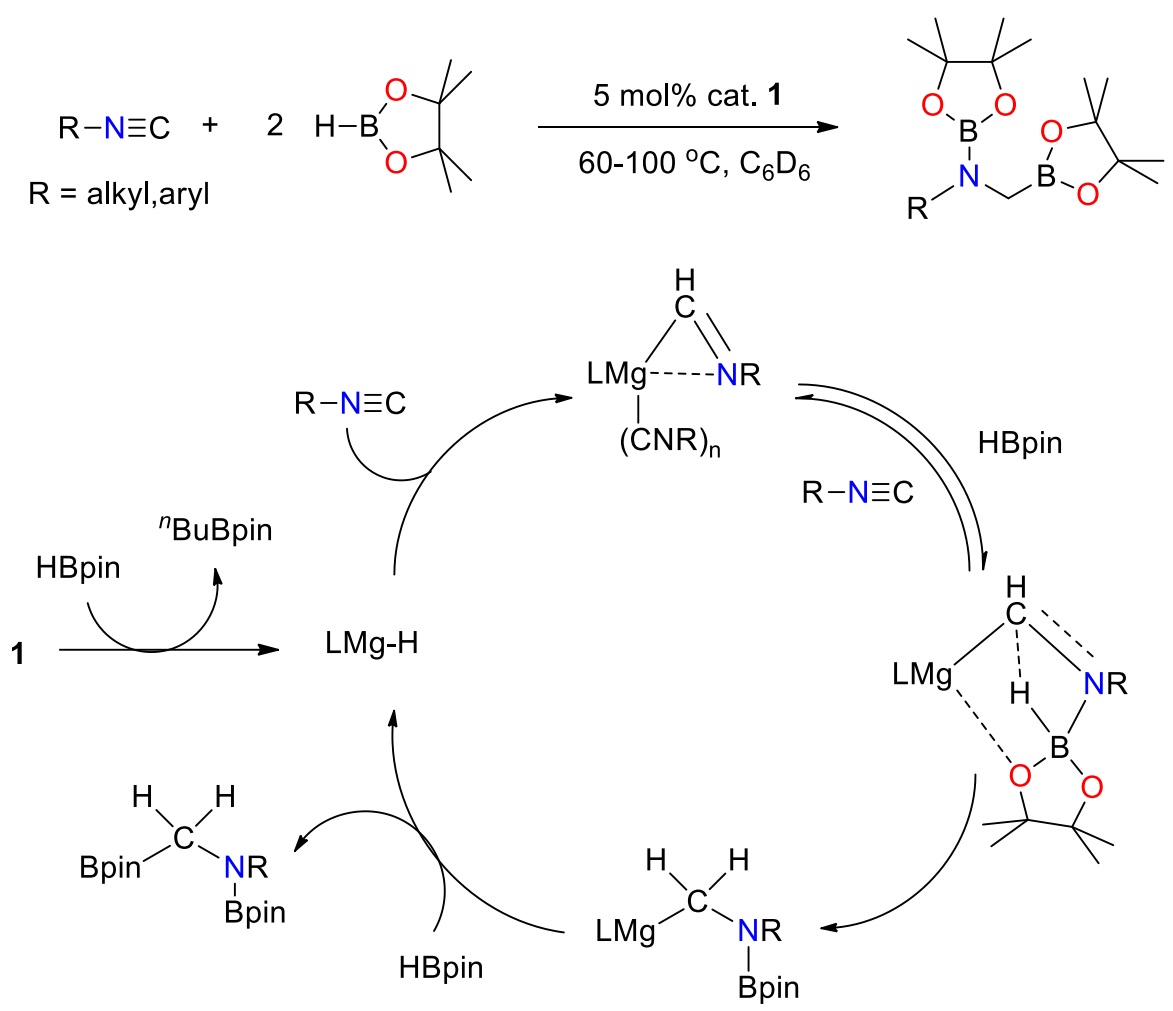

Scheme 22. Hydroboration of isonitriles by catalyst 1 and the most plausible mechanism for the synthesis of 1,2-diborylated amines.
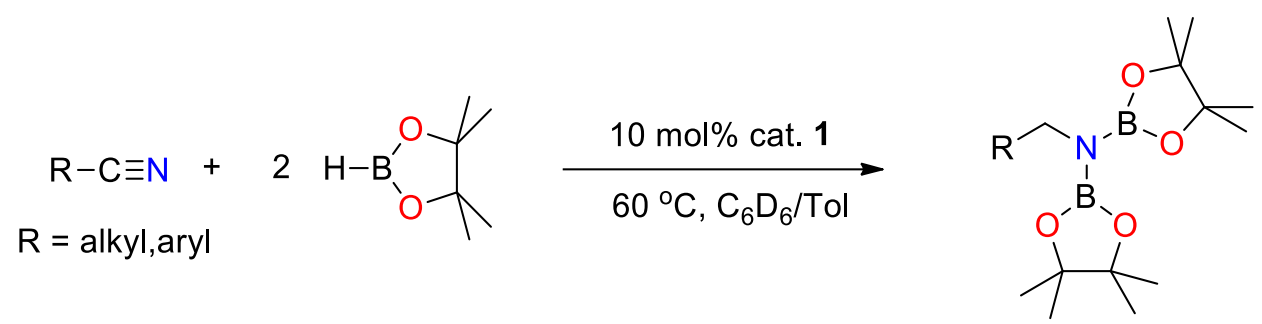

Scheme 23. $\mathrm{Mg}(\mathrm{II})$-catalyzed reduction of organic nitriles.

An earlier discussion stated the $\mathrm{Mg}(\mathrm{I})$ complex 11 developed by Ma research group accomplished the reduction of $\mathrm{C} \equiv \mathrm{N}$ group of organic nitriles. While utilizing $10 \mathrm{~mol} \%$ of complex 11, hydroboration of a range of nitriles with HBpin for the synthesis of bis(boryl)amines was also achieved (Scheme 7). ${ }^{59}$

\subsection{Hydroelementation reactions of alkenes.}

Parkin et al. in 2017 developed a unique magnesium carbatrane complex [Tism $\left.{ }^{i \operatorname{PrBenz}}\right] \mathrm{MgH}$ 19 as described earlier holding a terminal hydride obtained from the reaction of [Tism $\left.{ }^{i \mathrm{PrBenz}}\right] \mathrm{MgMe}$ 
and $\mathrm{PhSiH}_{3}{ }^{79} \mathrm{~A}$ variety of carbatrane derivatives involving a series of $\mathrm{Mg}$-functional groups [Tism $\left.{ }^{\text {PriBenz }}\right] \mathrm{MgX}\left[\mathrm{X}=\mathrm{F}, \mathrm{Cl}, \mathrm{Br}, \mathrm{I}, \mathrm{SH}, \mathrm{N}(\mathrm{H}) \mathrm{Ph}, \mathrm{CH}(\mathrm{Me}) \mathrm{Ph}, \mathrm{O}_{2} \mathrm{CMe}, \mathrm{S}_{2} \mathrm{CMe}\right.$ ] have been achieved from [Tism $\left.{ }^{i \mathrm{PrBenz}}\right] \mathrm{MgH}$. Catalyst 19 was further employed for the reduction of unsaturated bonds. Catalytic hydrosilylation and hydroboration of styrene substrates leading to Markovnikov products, hydroboration of carbodiimides, and pyridine were efficiently executed by using complex 19 (Scheme 24). The mechanistic pathway occurs via the insertion of styrene to catalyst 19 acquiring 1-phenylethyl derivative of $\mathrm{Mg}$ (II) complex. The addition of phenylsilane finally eliminates the hydrosilylated product.
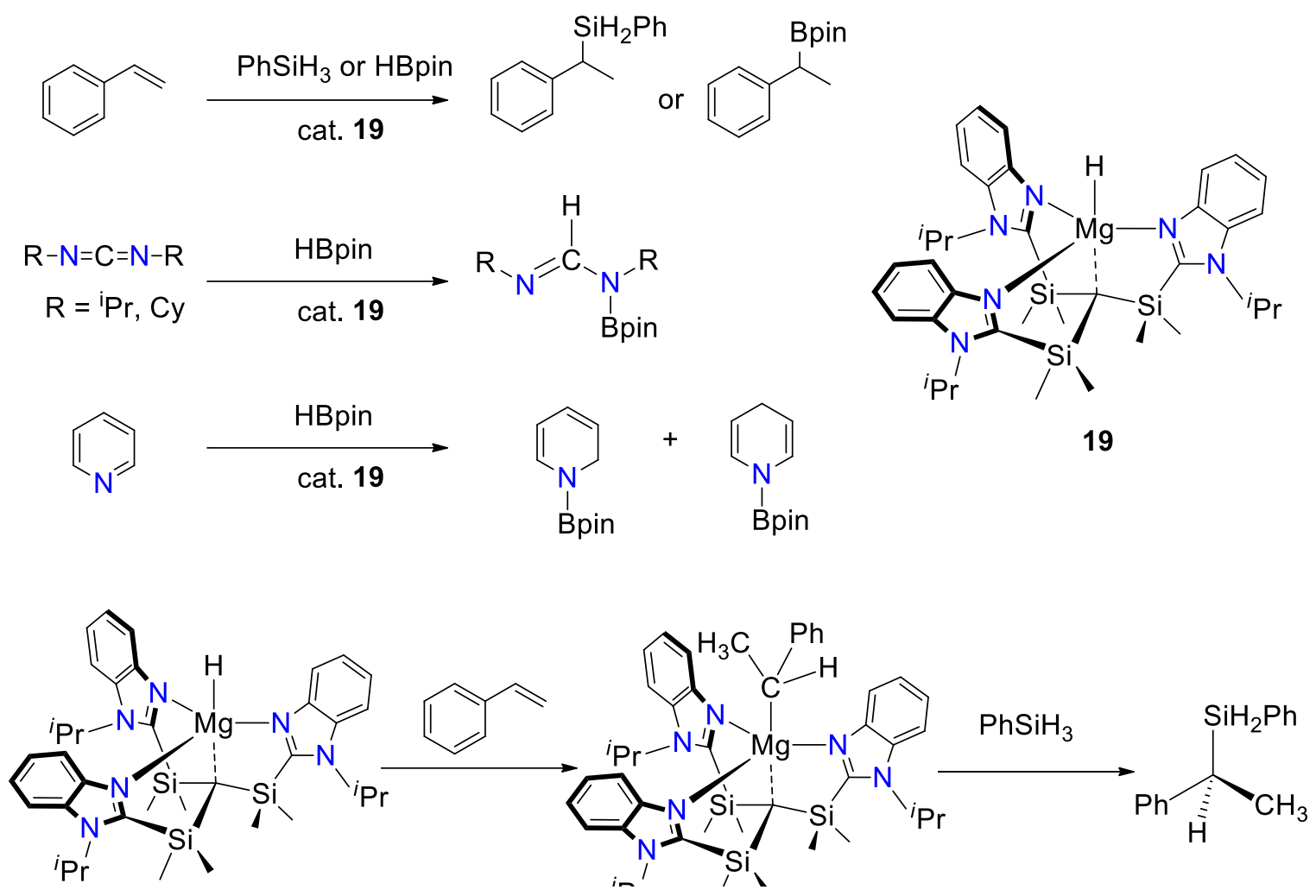

Scheme 24. Hydrosilylation and hydroboration of unsaturated substrates by [Tism $\left.{ }^{i \mathrm{PrBenz}}\right] \mathrm{MgH}$ catalyst 19.

As documented by the Hevia research group, catalytic hydroamination of styrenes was achieved with high yields, although with limitations in the substrate scope, in presence of heterobimetallic [(PMDETA $\left.)_{2} \mathrm{~K}_{2} \mathrm{Mg}\left(\mathrm{CH}_{2} \mathrm{SiMe}_{3}\right)_{4}\right]$ catalyst (Scheme 20). ${ }^{75}$ Recently, Hill and coworkers applied efficient dimeric $\beta$-diketiminato hydridomagnesium complex $\mathbf{2}$ and their derivatives that react with $\mathrm{C}-\mathrm{C}$ unsaturated substrates, offering corresponding organomagnesium 
complexes. The rate-determining steps and the $\mathrm{Mg}-\mathrm{H} / \mathrm{C}=\mathrm{C}$ insertion process were calculated from DFT studies. ${ }^{80}$ Scheme 25 sets out an example of the alkene insertion to dinuclear $\mathrm{Mg}(\mathrm{II})-\mathrm{H}$ catalyst, in which magnesium cyclopentylmethyl derivative $\mathbf{2 2}$ is readily obtained on reacting $\mathbf{2}$ with 1,5-hexadiene. Catalytic hydrosilylation of terminal alkenes with $\mathrm{PhSiH}_{3}$ was achieved with $\mathrm{Mg}-\mathrm{H} / \mathrm{C}=\mathrm{C}$ insertion providing anti-Markovnikov products.
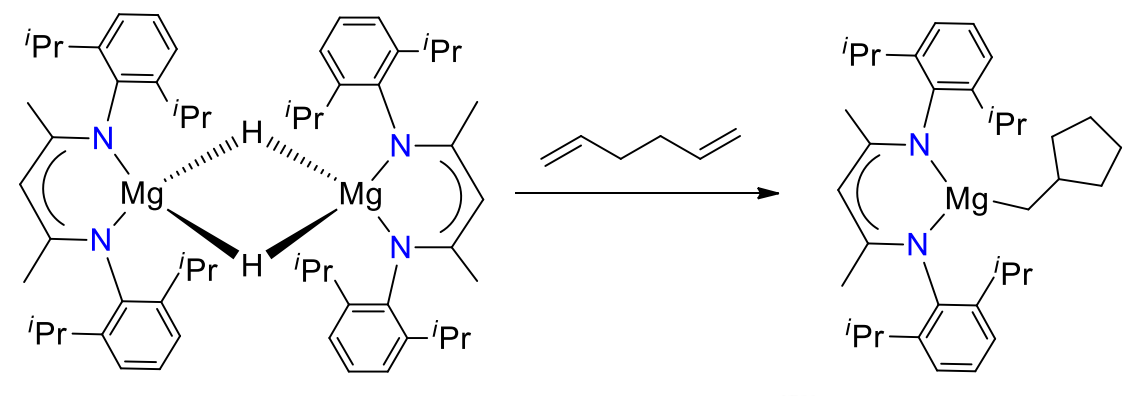

2

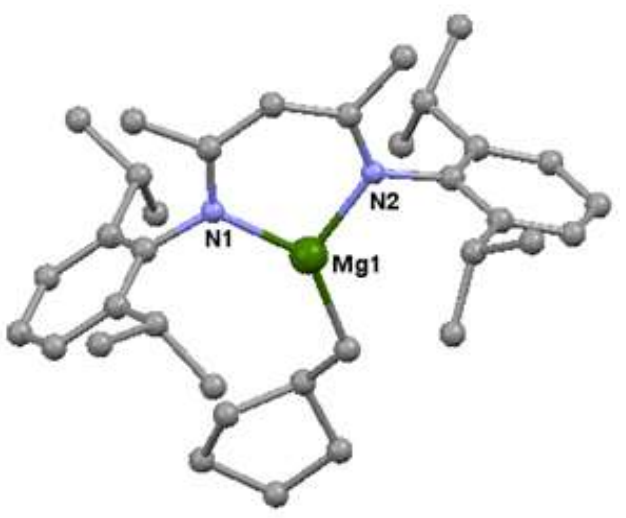

22

Scheme 25. Synthesis of magnesium cyclopentyl methyl complex 22 obtained by alkene insertion to 2. The solid-state structure of magnesium cyclopentyl methyl complex 22. Hydrogen atoms are omitted for clarity. CCDC 1912200. See ref. 80.

\subsection{Hydroelementation reactions of heterocumulenes.}

Furthermore, Hill et al. provided a fascinating protocol for the hydrodeoxygenation of isocyanates by employing $\mathrm{Mg}$ (II) complex $1 .^{81} 10 \mathrm{~mol} \%$ of catalyst 1 was used for the reduction of the $\mathrm{C}=\mathrm{O}$ bond of isocyanates using three molar equivalents pinacolborane at $60{ }^{\circ} \mathrm{C}$ within 1.5 24 hours of reaction time to afford $N$-borylated- $N$-methylamine, as shown in Scheme 26. The $\mathrm{Mg}(\mathrm{II})$ complex 1 as contributed by the Hill research group was also executed hydroboration reaction of carbodiimides efficiently with moderate to good yields. Additionally, Lan and Bai carried out DFT calculations for the mechanistic pathway for the hydroboration of carbodiimides promoted by the alkaline-earth metals. The theoretical results provided excellent distinction of the 
reaction pathways by the variation in alkaline-earth metal complexes. The studies revealed that $\mathrm{Mg}-\mathrm{H}$ is the active intermediate formed when magnesium complex $\mathbf{1}$ was utilized for hydroboration of carbodiimides. Differently, when calcium and strontium analogs were used, amide-metal intermediate generating from carbodiimide insertion into metal hydride behaves as the active catalytic species. This variation of the reaction mechanism could be attributed to the larger ionic radius of calcium and strontium with respect to magnesium. ${ }^{82}$

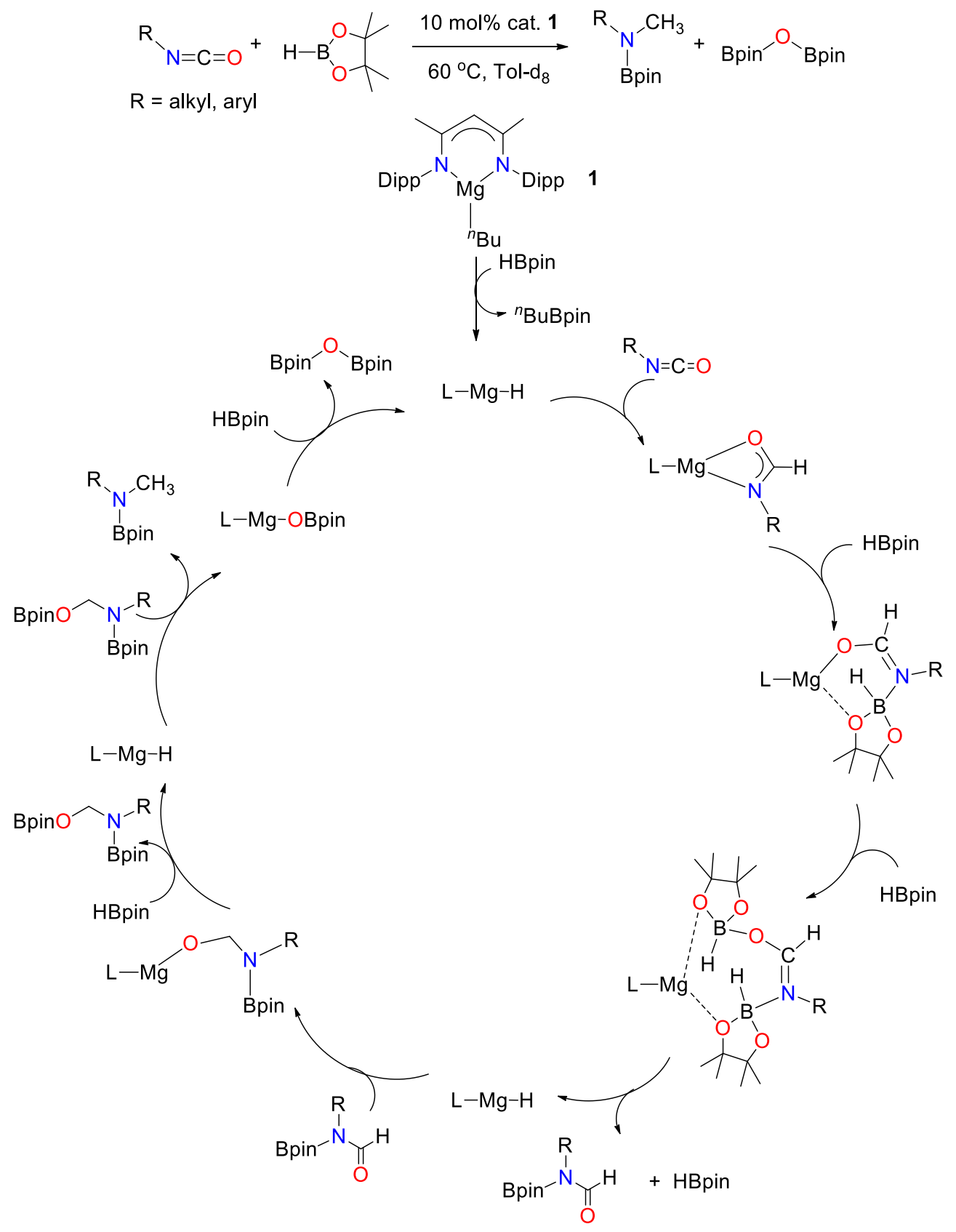

Scheme 26. $\operatorname{Mg}(\mathrm{II})$-catalyzed hydroboration and reduction of isocyanates. 
The magnesium carbatrane complex [Tism $\left.{ }^{i \text { PrBenz }}\right] \mathrm{MgH} 19$ as developed by Parkin research group was accomplished hydroboration of carbodiimides competently (Scheme 23). ${ }^{79}$ Novel magnesium amidinate complexes 23-24 and stable magnesium hydrides 25-26 have been reported quite recently. The $\mathrm{Mg}(\mathrm{II})$ catalysts $\mathbf{2 2 - 2 6}$ effectively mediated hydroboration of $N, N^{\prime}-$ diidopropylcarbodiimide, and Tishchenko reaction on benzaldehyde. ${ }^{83}$ The complex 25 reacted readily with phenylacetylene stoichiometrically, eliminating dihydrogen and the formation of a new complex 27 was observed (Scheme 27). Figure 5 shows the molecular structure of 27 thus confirmed from single-crystal X-ray diffraction analysis. Higher the sterically hindered $\beta$ diketiminate ligand, higher stability of the $\mathrm{Mg}-\mathrm{H}$ core was observed, however reducing the reactivity toward the unsaturated substrates. Monomeric $\mathrm{Mg}-\mathrm{H}$ complexes thus displayed higher catalytic efficiency than the aggregated structures.
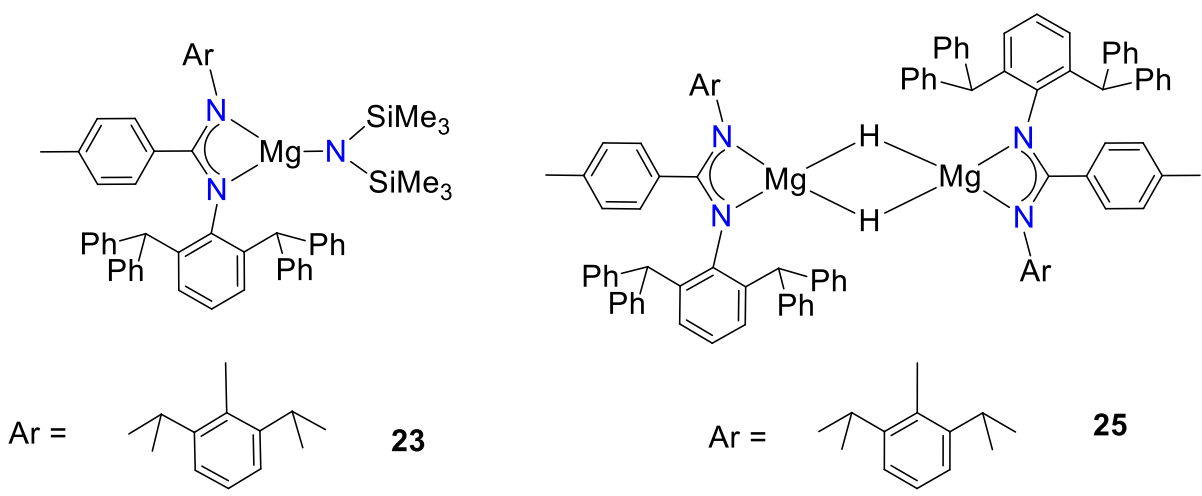

25
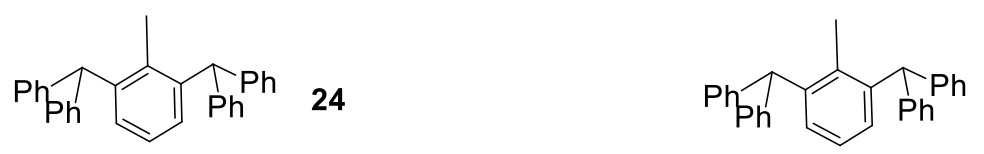

26

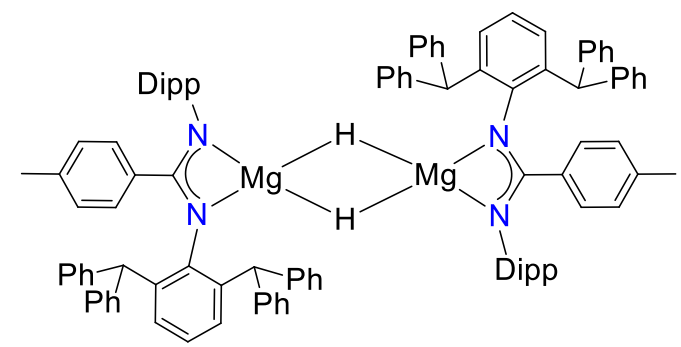

25

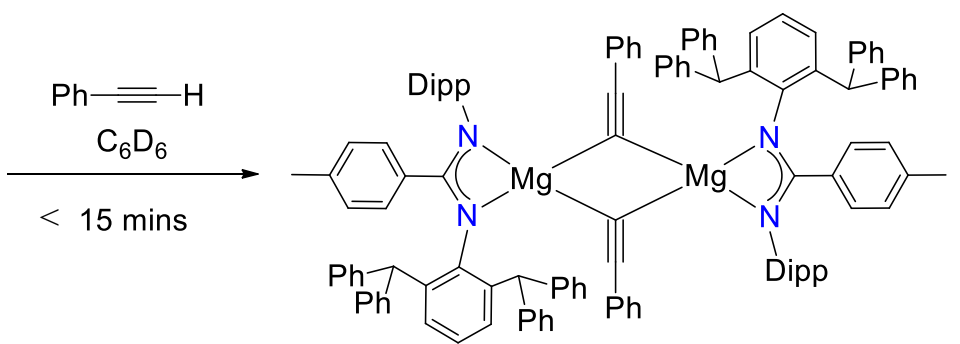

27

Scheme 27. Magnesium amidinate and hydride complexes 23-26 for hydroboration reactions of $N, N^{\prime}$-diidopropylcarbodiimide and Tishchenko reaction. The synthetic pathway of complex 27. 


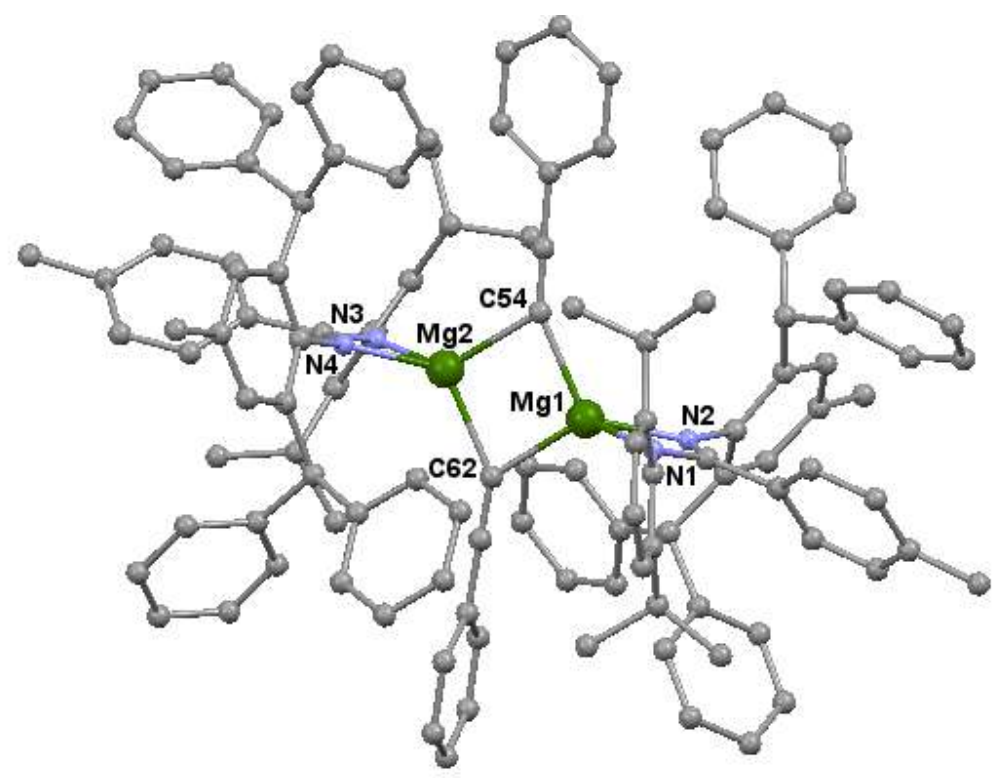

Figure 5. $\mathrm{Mg}$ (II) complex 27 formed from 25 and phenylacetylene. Hydrogen atoms are omitted for clarity. CCDC 2016831. See ref. 83.

\subsection{Miscellaneous.}

The Hevia research group published two magnesium complexes 28-29 and 1 derived from the $\beta$-ketiminate ligand which is highly effective for the functionalization of fluoroarenes and promotion of $\mathrm{C}-\mathrm{F}$ bond activation processes. ${ }^{84}$ Metallation of fluorinated arenes was achieved in presence of one equivalent amount of $\mathbf{2 8}$ within 1 hour and at room temperature by the promotion of $\mathrm{C}-\mathrm{H}$ bond activation. $\mathrm{C}-\mathrm{H}$ acidity facilitated as the $\mathrm{F}$ atoms increased in the fluoroarene substrates, providing higher conversion of the metallated products. The metallated products were utilized further to undergo Negishi cross-coupling reactions using stoichiometric amounts of $\mathrm{ZnCl}_{2}, 10 \mathrm{~mol} \% \mathrm{Pd}\left(\mathrm{PPh}_{3}\right)_{3}$, and two equivalents of iodobenzene (Scheme 28). Scheme 29 sets out complexes 1 and 29 promoted an alternative reaction pathway describing the coordination step, followed by $\mathrm{C}-\mathrm{C}$ bond formation and fluoride elimination process for acquiring the final crosscoupled product. 

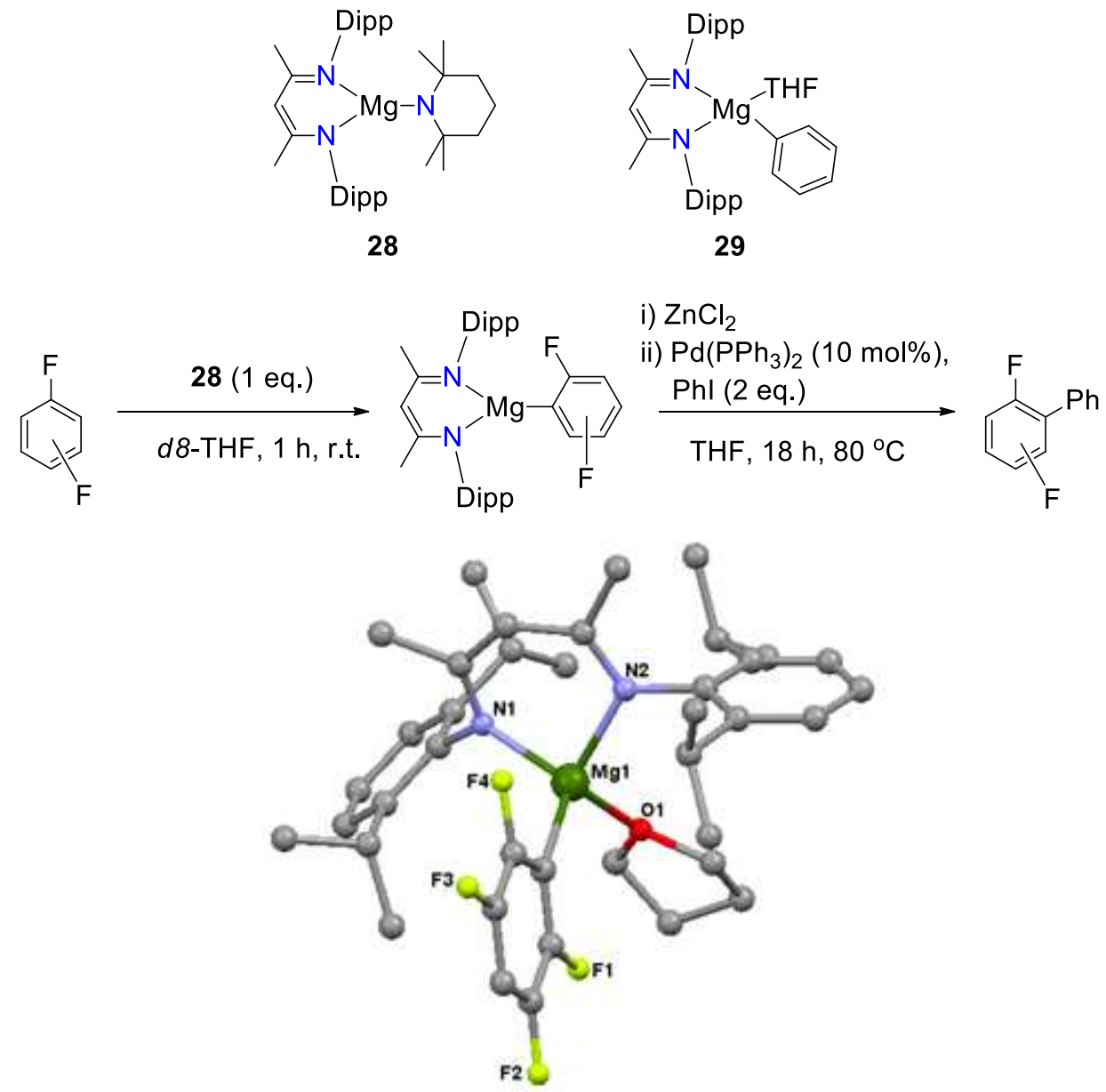

Scheme 28. $\operatorname{Mg}(\mathrm{II})$ complex promoted metalation of fluoroarenes followed by Negishi crosscoupling reaction. The molecular structure of the magnesiated product of 1,2,4,5tetrafluorobenzene. Hydrogen atoms are omitted for clarity. CCDC No. 1567107. See Ref. 84. 


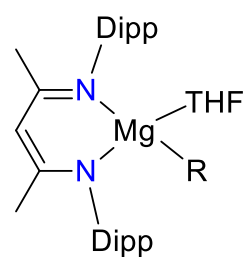

$\mathrm{R}=\mathrm{Bu}(1)$

$\mathrm{Ph}(15)$

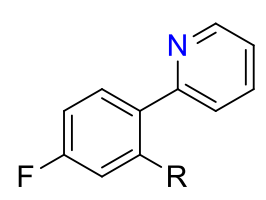

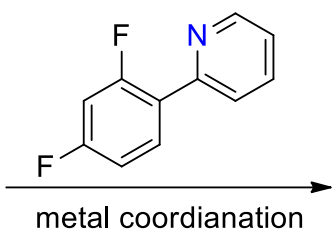

metal coordianation
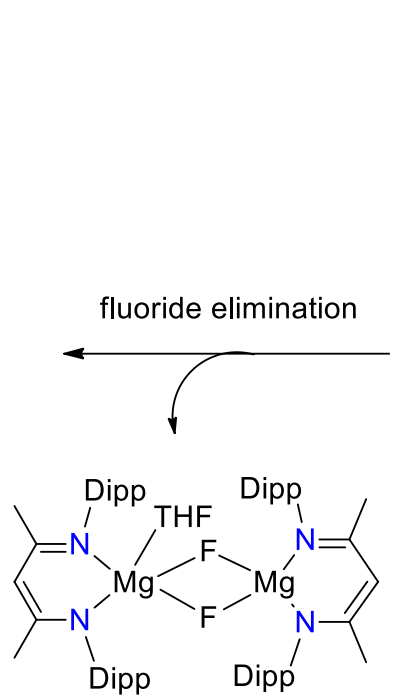

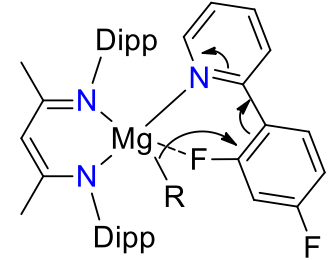

C-C bond formation

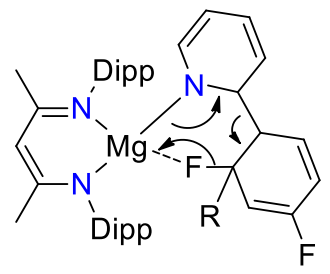

Scheme 29. A most plausible mechanism for Mg-promoted $\mathrm{C}-\mathrm{F}$ alkylation.

Lately, an important review was documented by Pellissier, specifying the considerable progress in enantioselective transformation by several chiral magnesium catalysts. ${ }^{85}$ A broad range of unsaturated substrates have been shown to undergo a variety of enantioselective domino and tandem reactions, ring-opening reactions, cycloaddition reactions, Michael reactions, hydroamination reactions, and many more in the presence of various chiral magnesium catalysts.

\section{Conclusion.}

This minireview discusses the various magnesium metal catalysts employed for the reduction of a series of unsaturated compounds in recent years. The catalytic addition of $\mathrm{E}-\mathrm{H}$ bonds $(\mathrm{E}=\mathrm{N}, \mathrm{P}$, $\mathrm{O}, \mathrm{S})$ to the multiple $\mathrm{C}-\mathrm{C}$ bonds of organic nitriles, alkynes, alkenes, aldehydes, ketones, enones, azines, and heterocumulenes has seen tremendous progress when research groups around the globe have employed several novel magnesium catalysts. Proficiency in designing and promoting magnesium metal complexes has developed significantly over the years. The corresponding products achieved from various hydroelementation reaction methodologies have been valuable, useful for laboratory and industrial purposes. 


\section{Acknowledgments}

This work was financially supported by the Indian Institute of Technology Hyderabad. I.B. thanks the Ministry of Human Resource and Development (MHRD), Government of India.

\section{Data availability statement}

The data that support the findings of this study are openly available in references.

\section{References}

[1] K. Kümmerer, Angew. Chem. Int. Ed. 2017, 56, 16420.

[2] C. Blum, D. Bunke, M. Hungsberg, E. Roelofs, A. Joas, R. Joas, M. Blepp, H. C. Stolzenberg, Sustain. Chem. Pharm. 2017, 5, 94.

[3] X. Zeng, Chem. Rev. 2013, 113, 6864 and references therein.

[4] (a) P. T. Anastas, J. C. Warner, Green Chemistry: Theory and Practice; Oxford University Press, 1998; (b) I. T. Horvath, P. T. Anastas, Chem. Rev. 2007, 107, 2169.

[5] R. H. Grubbs, Angew. Chem. Int. Ed. 2006, 45, 3760.

[6] (a) N. Miyaura, A. Suzuki, Chem. Rev. 1995, 95, 2457; (b) M. L. Crawley, B. M. Trost, H. C. Shen, Selected Applications of Transition Metal-Catalyzed Carbon-Carbon Cross-Coupling Reactions in the Pharmaceutical Industry; Wiley-VCH: Weinheim, 2012.

[7] A. Holleman, N. Wiberg, Textbook of Inorganic Chemistry, 1985, 33, 1486.

[8] I. P. Beletskaya, A. V. Cheprakov, Chem. Rev. 2000, 100, 3009.

[9] P. P. Power, Nature 2010, 463, 171.

[10] (a) J. Spielmann, G. Jansen, H. Bandmann, S. Harder, Angew. Chem. Int. Ed. 2008, 47, 6290; (b) J. Spielman, S. Harder, J. Am. Chem. Soc. 2009, 131, 5064.

[11] (a) D. J. Liptrot, M. S. Hill, M. F. Mahon, D. J. MacDougall, Chem. Eur. J. 2010, 16, 8508; (b) J. Spielmann, D. F. J. Piesik, S. Harder, Chem. Eur. J. 2010, 16, 8307; (c) M. S. Hill, M. Hodgson, D. J. Liprot, M. F. Mahon, Dalton Trans. 2011, 40, 7783-7790. 
[12] (a) S. Slomkowski, S. Penczek, A. Duda, Polym. Adv. Technol. 2014, 25, 436; (b) S. Mecking, Angew. Chem. Int. Ed. 2004, 43, 1078; (b) M. S. Hill, G. Kociok-Köhn, T. P. Robinson, Chem. Commun. 2010, 46, 7587.

[13] (a) A. Pilone, K. Press, I. Goldberg, M. Kol, M. Mazzeo, M. Lamberti, M. Gradient. J. Am. Chem. Soc. 2014, 136, 2940; (b) C. Tsai, H. Du, J. Chang, B. Huang, B. Ko, C. Lin, RSC Adv. 2014, 4, 14527.

[14] (a) N. Nimitsiriwat, V. C. Gibson, E. L. Marshall, M. R. Elsegood, Inorg. Chem. 2008, 47, 5417; (b) Z. Mou, B. Liu, M. Wang, H. Xie, P. Li, L. Li, S. Li, D. Cui, Chem. Commun. 2014, 50, 11411.

[15] (a) F. Feil, S. Harder, Organometallics 2000, 19, 5010; (b) M. Westerhausen, M. Grtner, R. Fischer, J. Langer, Angew. Chem. 2007, 119, 1994; (c) M. R. Crimmin, I. J. Casely, M. S. Hill, J. Am. Chem. Soc. 2005, 127, 2042.

[16] (a) Y. Sun, J. Xiong, Z. Dai, X. Pan, N. Tang, J. Wu, Inorg. Chem. 2015, 55, 136; (b) S. Kobayashi, Y. Yamashita, Acc. Chem. Res. 2010, 44, 58.

[17] J. D. Smith, Angew. Chem. Int. Ed. 2009, 48, 6597.

[18] J. Spielmann, G. Jansen, H. Bandmann, S. Harder, Angew. Chem. Int. Ed. 2008, 47, 6290.

[19] (a) F. Buch, S. Harder, Organometallics 2007, 26, 5132; (b) R. E. Mulvey, S. D. Robertson, Angew. Chem. Int. Ed. 2013, 52, 11470; (c) P. Bellham, M. S. Hill, G. KociokKöhn, Dalton Trans. 2015, 44, 12078.

[20] S. Bogaert, J. F. Carpentier, T. Chenal, A. Mortreux, G. Ricart, Macromol. Chem. Phys. 2000, 201, 1813; (b) S. Harder, F. Feil, K. Knoll, Angew. Chem. Int. Ed. 2001, 40, 4261 .

[21] (a) N. Nimitsiriwat, V. C. Gibson, E. L. Marshall, M. R. Elsegood, Inorg. Chem. 2008, 47, 5417; (b) A. F. Douglas, B. O. Patrick, P. Mehrkhodavandi, Angew. Chem. Int. Ed. 2008, 47, 2290; (c) A. Pilone, K. Press, I. Goldberg, M. Kol, M. Mazzeo, M. Lamberti, J. Am. Chem. Soc. 2014, 136, 2940. 
[22] (a) Y. Motoyama, H. Nishiyama, in Lewis Acids in Organic Synthesis (Ed.: H. Yamamoto), WileyVCH, Weinheim, 2000, 59; (b) S. Harder, Alkaline-Earth Metal Compounds: Oddities and Applications, Springer, Berlin, 2013.

[23] (a) M. R. Crimmin, M. S. Hill, Top. Organomet. Chem. 2013, 45, 191; (b) K. Revunova, G. I. Nikonov, Dalton Trans. 2015, 44, 840.

[24] (a) N. L. Lampland, A. Pindwal, S. R. Neal, S. Schlauderaff, A. Ellern, A. D. Sadow, Chem. Sci. 2015, 6, 6901; (b) M. Arrowsmith, M. S. Hill, G. Kociok-Köhn, Chem. Eur. J. 2013, 19, 2776; (c) N. L. Lampland, M. Hovey, D. Mukherjee, A. D. Sadow, ACS Catal. 2015, 5, 4219; (d) T. Hadlington, C. Weetman, G. Kociok-Köhn, M. S. Hill, M. Arrowsmith, Organometallics 2011, 30, 5556.

[25] (a) S. D. Roughley, A. M. Jordan J. Med. Chem. 2011, 54, 3451; (b) J. F. Hartwig, Nature 2008, 455, 314.

[26] X. Zeng, Chem. Rev. 2013, 113, 6864 and references cited therein.

[27] (a) W. Ren, G. Zi, D. C. Fang, M. D. Walter, Chem. Eur. J. 2011, 17, 12669; (b) B. D. Stubbert, T. J. Marks, J. Am. Chem. Soc. 2007, 129, 6149; (c) B. D. Stubbert, T. J. Marks, J. Am. Chem. Soc. 2007, 129, 4253; (d) A. Haskel, T. Straub, M. S. Eisen, Organometallics 1996, 15, 3773; (e) C. E. Hayes, R. H. Platel, L. L. Schafer, D. B. Leznoff, Organometallics 2012, 31, 6732.

[28] Z. Yang, M. Zhong, X. Ma, S. De, C. Anusha, P. Parameswaran, H. W. Roesky, Angew. Chem. 2015, 127, 10363.

[29] (a) A. K. Dash, J. Q. Wang, M. S. Eisen, Organometallics 1999, 18, 4724.

[30] (a) C. J. Weiss, S. D. Wobser, T. J. Marks, J. Am. Chem. Soc. 2009, 131, 2062; (b) C. J. Weiss, S. D. Wobser, T. J. Marks, Organometallics 2010, 29, 6308; (c) C. J. Weiss, T. J. Marks, Dalton Trans. 2010, 39, 6576.

[31] (a) A. Haskel, T. Straub, A. K. Dash, M. S. Eisen, J. Am. Chem. Soc. 1999, 121, 3014; (b) T. Straub, A. Haskel, M. S. Eisen, J. Am. Chem. Soc. 1995, 117, 6364. 
See the original article: Applied Organometallic Chemistry, 2021, Doi: 10.1002/aoc.6333

[32] (a) J. S. Ryu, T. J. Marks, F. E. McDonald, J. Org. Chem. 2004, 69, 1038; (b) A. M. Seyam, B. D. Stubbert, T. R. Jensen, J. J. O'Donnell III, C. L. Stern, T. J. Marks, Inorg. Chim. Acta 2004, 357, 4029; (c) S. A. Ryken, L. L. Schafer, Acc. Chem. Res. 2015, 48, 2576.

[33] (a) M. C. Wood, D. C. Leitch, C. S. Yeung, J. A. Kozak, L. L. Schafer, Angew. Chem. Int. Ed. 2007, 46, 354; (b) A. Takemiya, J. F. Hartwig, J. Am. Chem. Soc. 2006, 128, 6042; (c) A. M. Johns, M. Utsunomiya, C. D. Incarvito, J. F. Hartwig, J. Am. Chem. Soc. 2006, 128, 1828; (d) C. F. Bender, R. A. Widenhoefer, J. Am. Chem. Soc. 2005, 127, 1070; (e) T. Straub, A. Haskel, T. G. Neyroud, M. Kapon, M. Botoshansky, M. S. Eisen, Organometallics 2001, 20, 5017.

[34] (a) D. V. Gribkov, K. C. Hultzsch, F. Hampel, J. Am. Chem. Soc. 2006, 128, 3748; (b) D. Riegert, J. Collin, A. Meddour, A. Schulz, A. Trifonov, J. Org. Chem. 2006, 71, 2514; (c) N. Meyer, A. Zulys, P. W. Roesky, Organometallics 2006, 25, 4179; (d) M. Rastatter, A. Zulys, P. W. Roesky, Chem. Eur. J. 2007, 13, 3606.

[35] (a) M. R. Crimmin, I. J. Casely, M. S. Hill, J. Am. Chem. Soc. 2005, 127, 2042; (b) S. Datta, P. W. Roesky, S. Blechert, Organometallics 2007, 26, 4392; (c) S. Datta, M. T. Gamer, P. W. Roesky, Organometallics 2008, 27, 1207.

[36] R. J. Batrice, M. S. Eisen, Chem. Sci. 2016, 7, 939.

[37] H. Liu, N. Fridman, M. Tamm, M. S. Eisen, Organometallics 2017, 36, 3896.

[38] I. S. R. Karmel, M. Tamm, M. S. Eisen, Angew. Chem. 2015, 127, 12599.

[39] R. J. Batrice, C. E. Kefalidis, L. Maron, M. S. Eisen, J. Am. Chem. Soc. 2016, 138, 2114.

[40] M. M. I. Basiouny, J. A. R Schmidt, Organometallics 2017, 36, 721.

[41] (a) S. M. Harling, H. Gorls, S. Krieck, M. Westerhausen, Inorg. Chem. 2016, 55, 10741; (b) S. M. Harling, B. E. Fener, S. Krieck, H. Gorls, M. Westerhausen, Organometallics 2018, 37, 4380.

[42] P. H. Martínez, K. C. Hultzsch, F. Hampel, Chem. Commun. 2006, 2221. 
See the original article: Applied Organometallic Chemistry, 2021, Doi: 10.1002/aoc.6333

[43] F. Buch, J. Brettar, S. Harder, Angew. Chem. Int. Ed. 2006, 45, 2741.

[44] V. Leich, K. Lamberts, T. P. Spaniol, J. Okuda, Dalton Trans. 2014, 43, 14315.

[45] N. T. Coles, M. F. Mahon, R. L. Webster, Chem. Comm. 2018, 54, 10443.

[46] B. Liu, T. Roisnel, J. F. Carpentier, Y. Sarazin, Angew. Chem. Int. Ed. 2012, 51, 4943.

[47] M. Arrowsmith, M. S. Hill, G. Kociok-Köhn, Organometallics 2014, 33, 206.

[48] M. R. Crimmin, A. G. M. Barrett, M. S. Hill, P. B. Hitchcock, P. A. Procopiou, Organometallics 2007, 26, 2953.

[49] H. Hu, C. Cui, Organometallics 2012, 31, 1208.

[50] (a) R. K. Kottalanka, A. Harinath, J. Bhattacharjee, H. V. Babu, T. K. Panda, Dalton Trans. 2014, 43, 8757; (b) J. Bhattacharjee, S. Das, D. N. Reddy, B. S. Mallik, T. K. Panda, Z. Anorg. Allg. Chem. 2016, 642, 118; (c) S. Anga, Y. Sarazin, J. F. Carpentier, T. K. Panda, ChemCatChem 2016, 8, 1373; (d) A. Harinath, S. Anga, T. K. Panda, RSC $A d v$. 2016, 6, 35648; (e) S. Anga, J. F. Carpentier, T. K. Panda, T. Roisnel, Y. Sarazin, $R S C A d v .2016,6,57835$; (f) A. Harinath, J. Bhattacharjee, S. Anga, T. K. Panda, Aus. J. Chem. 2017, 70, 727.

[51] (a) A. Harinath, J. Bhattacharjee, H. P. Nayek, T. K. Panda, Dalton Trans. 2018, 47, 12613; (b) I. Banerjee, A. Harinath, T. K. Panda, Eur. J. Inorg. Chem. 2019, 2224; (c) A. Harinath, J. Bhattacharjee, A. Sarkar, T. K. Panda, New J. Chem. 2019, 43, 8882; (d) J. Bhattacharjee, A. Harinath, A. Sarkar, T. K. Panda, Chem. Asian J. 2020, 15, 860; (e) I. Banerjee, S. Sagar, T. K. Panda, Appl. Organomet. Chem. 2020, 34, e5765; (f) K. Bano, S. Anga, A. Jain, H. P. Nayek, T. K. Panda, New J. Chem. 2020, 44, 9419; (g) I. Banerjee, S. Sagar, T. K. Panda, Org. Biomol. Chem. 2020, 18, 4231.

[52] M. Arrowsmith, T. J. Hadlington, M. S. Hill, G. Kociok-Kohn, Chem. Commun. 2012, $48,4567$.

[53] J. Intemann, M. Lutz, S. Harder, Organometallics 2014, 33, 5722.

[54] D. Mukherjee, A. Ellern, A. D. Sadow, Chem. Sci. 2014, 5, 959.

[55] C. Weetman, M. S. Hill, M. F. Mahon, Polyhedron 2016, 103, 115. 
[56] (a) K. Manna, T. Zhang, F. X. Greene, W. Lin, J. Am. Chem. Soc. 2015, 137, 2665; (b) K. Manna, P. Ji, F. X. Greene, W. Lin, J. Am. Chem. Soc. 2016, 138, 7488.

[57] M. K. Barman, A. Baishya, S. Nembenna, Dalton Trans. 2017, 46, 4152.

[58] M. Ma, J. Li, X. Shen, Z. Yu, W. Yao, S. A. Pullarkat, $R S C A d v .2017,7,45401$.

[59] J. Li, M. Luo, X. Sheng, H. Hua, W. Yao, S. A. Pullarkat, L. Xu, M. Ma, Org. Chem. Front. 2018, 5, 3538.

[60] S. Yadav, R. Dixit, M. K. Bisai, K. Vanka, S. S. Sen, Organometallics 2018, 37, 4576.

[61] A. Falconnet, M. Magre, B. Maity, L. Cavallo, M. Rueping, Angew. Chem. 2019, 131, 17731.

[62] M. Szewczyk, M. Magre, V. Zubar, M. Rueping, ACS Catal. 2019, 9, 11634.

[63] Y. K. Jang, M. Magre, M. Rueping, Org. Lett. 2019, 21, 8349.

[64] Y. Li, M. Wu, H. Chen, D. Xu, L. Qu, J. Zhang, R. Bai, Y. Lan, Front. Chem. 2019, 7. Article 149.

[65] M. Magre, M. Szewczyk, M. Rueping, Org. Lett. 2020, 22, 3209.

[66] X. Cao, W. Wang, K. Lu, W. Yao, F. Xue, M. Ma, Dalton Trans. 2020, 49, 2776.

[67] W. Wang, K. Lu, Y. Qin, W. Yao, D. Yuan, S. A. Pullarkat, L. Xu, M. Ma, Tetrahedron 2020, 76, 131145.

[68] V. Vasilenko, C. K. Blasius, H. Wadepohl, L. H. Gade, Chem. Commun. 2020, 56, 1203.

[69] M. D. Anker, M. Arrowsmith, P. Bellham, M. S. Hill, G. Kociok-Kohn, D. J. Liptrot, M. F. Mahon, C. Weetman, Chem. Sci. 2014, 5, 2826.

[70] M. D. Anker, M. S. Hill, J. P. Lowe, M. F. Mahon, Angew. Chem. Int. Ed. 2015, 54, 10009.

[71] D. Mukherjee, S. Shirase, T. P. Spaniol, K. Mashima, J. Okuda, Chem. Commun. 2016, 52, 13155. 
[72] M. Rauch, G. Parkin, J. Am. Chem. Soc. 2017, 139, 18162.

[73] A. Chatupheeraphat, M. Rueping, M. Magre, Org. Lett. 2019, 21, 9153.

[74] M. Magre, B. Maity, A. Falconnet, L. Cavallo, M. Rueping, Angew. Chem. Int. Ed. 2019, 58,7025 .

[75] L. Davin, A. Hernán-Gómez, C. McLaughlin, A. R. Kennedy, R. McLellan, E. Hevia, Dalton Trans. 2019, 48, 8122.

[76] M. Magre, M. Szewczyk, M. Rueping, Org. Lett. 2020, 22, 1594.

[77] C. Weetman, M. S. Hill, M. F. Mahon, Chem. Commun. 2015, 51, 14477.

[78] C. Weetman, M. D. Anker, M. Arrowsmith, M. S. Hill, G. Kociok-Kohn, D. J. Liptrot, M. F. Mahon, Chem. Sci. 2016, 7, 628.

[79] M. Rauch, S. Ruccolo, G. Parkin, J. Am. Chem. Soc. 2017, 139, 13264.

[80] L. Garcia, C. Dinoi, M. F. Mahon, L. Maron, M. S. Hill, Chem. Sci. 2019, 10, 8108.

[81] Y. Yang, M. D. Anker, J. Fang, M. F. Mahon, L. Maron, C. Weetman, M. S. Hill, Chem. Sci. 2017, 8, 3529.

[82] D. Xu, C. Shan, R. Bai, Y. Lan, Chinese J. Org. Chem. 2017, 37, 1231.

[83] C. Bakewell, Dalton Trans. 2020, 49, 11354.

[84] L. Davin, R. McLellan, A. R. Kennedy, E. Hevia, Chem. Commun. 2017, 53, 11650.

[85] H. Pellissier, Org. Biomol. Chem. 2017, 15, 4750. 